Check for updates

Cite this: RSC Adv., 2017, 7, 54291

Received 27th September 2017 Accepted 7th November 2017

DOI: 10.1039/c7ra10713g

rsc.li/rsc-advances

\section{Insight into mechanisms of fluoride removal from contaminated groundwater using lanthanum- modified bone waste}

\author{
Lanting Wang, ${ }^{\text {ab }}$ Yanhua Xie, (iD *ab Jinglong Yang, ${ }^{\text {ab }}$ Xueqian Zhu, ${ }^{\text {ab }}$ Qili Hu, ${ }^{\mathrm{c}}$ \\ Xiaoyun $\mathrm{Li}^{\mathrm{ab}}$ and Zhuang Liu ${ }^{\mathrm{ab}}$
}

The current worldwide issue of fluoride contamination in groundwater has resulted in an increased demand for efficient adsorbents. Meanwhile discard and landfill of bone waste has led to environmental pollution. In order to achieve bone waste recycling and enhance the efficiency of fluoride removal, a lanthanummodified bone waste (LBW) composite was synthesized and tested to remove fluoride from contaminated groundwater. The adsorbent characterization was conducted by SEM, BET, XRD, FTIR and XPS. The fluoride adsorption performance was evaluated by batch experiments. SEM and BET revealed that the introduction of lanthanum could modify the porous structure of the adsorbent and enhance its specific surface area. The LBW composite had a high $\mathrm{pH}_{\mathrm{zpc}}$ of 11.4 and the fluoride adsorption was barely affected by the solution $\mathrm{pH}$ over a wide $\mathrm{pH}$ range of 2.5-10.0. The influence of common coexisting oxygen anions in the range of $0-100 \mathrm{mg} \mathrm{L}^{-1}$ was not significant. The fluoride adsorption was a typical chemisorption process and followed PSO and F-L PSO equations. The FVER model provided a more accurate prediction of a larger surface coverage degree with respect to equilibrium at the initial stage during adsorption of fluoride. Isotherm studies revealed that the reaction obeyed the Langmuir model, indicating that this process was monolayer adsorption. Possible defluoridation and regeneration were proposed. The fluoride adsorption was mainly controlled by the processes of electrostatic attraction on the LBW surface with a positive charge and ion exchange between fluoride and hydroxide ions. This research provides an alternative method for fluoride removal from contaminated groundwater in practical applications.

\section{Introduction}

Fluoride contamination in groundwater has been recognized as one of the increasingly serious worldwide environmental problems and has received considerable attention for many years. ${ }^{1}$ The breakdown and leaching of fluoride bearing rocks and soils, the runoff from agricultural fields and the uncontrolled discharge from industrial establishments are primarily responsible for fluoride contamination. ${ }^{2}$ The fluoride content is a function of many factors, such as the availability and solubility of fluoride minerals, the velocity of groundwater, $\mathrm{pH}$, temperature, and the concentration of calcium and bicarbonate ions. $^{3}$ As an essential micronutrient of the human body,

${ }^{a}$ State Key Laboratory of Geohazard Prevention and Geoenvironment Protection, College of Environment, Chengdu University of Technology, Chengdu 610059, China. E-mail: xieyanhua10@cdut.cn; Fax: +86 15928561958; Tel: +8615928561958 ${ }^{b}$ State Environmental Protection Key Laboratory of Synergetic Control and Joint Remediation for Soil \& Water Pollution, College of Environment, Chengdu University of Technology, Chengdu 610059, China

${ }^{c}$ Graduate School of Life and Environmental Sciences, University of Tsukuba, 1-1-1 Tennodai, Tsukuba, Ibaraki 305-8572, Japan whether fluoride in drinking water is beneficial to human health depends on its concentration and the duration of continuous uptake. ${ }^{4}$ Low concentrations of fluoride in drinking water can prevent dental caries and facilitate the mineralization of hard tissues, ${ }^{5}$ while high concentrations of fluoride can contribute to various physical disorders, including dental and skeletal fluorosis, infertility, brain damage and thyroid disorder. ${ }^{6}$ It is estimated that more than 200 million people worldwide rely on drinking water with a fluoride concentration that exceeds $1.5 \mathrm{mg} \mathrm{L}^{-1}$ (ref. 7) and high fluoride concentrations in groundwater can be found in many parts of the world, particularly in parts of India, China, Central Africa and South America. ${ }^{8}$ Therefore, the fast and effective removal of fluoride is of prime importance for providing safe drinking water and maintaining sustainable water resources.

Various techniques have been developed to remove fluoride from aqueous solution, including precipitation, ${ }^{\mathbf{9}}$ adsorption, ${ }^{\mathbf{1 0}}$ electrocoagulation, ${ }^{\mathbf{1 1}}$ ion exchange, ${ }^{\mathbf{1 2}}$ reverse osmosis, ${ }^{\mathbf{1 3}}$ and electrodialysis. ${ }^{\mathbf{1 4}}$ Among these methods, adsorption has developed very mature for defluoridation of water due to its low maintenance cost, flexible operation and simple design. ${ }^{15}$ The viability of such a technique is greatly dependent on the 
development of suitable adsorptive materials. The adsorbents available for treatment of fluoride include activated alumina, ${ }^{16}$ bone char, ${ }^{17}$ hydroxyapatite (HAP),${ }^{18}$ chitosan, ${ }^{19}$ activated carbon $^{20}$ and zeolite-based adsorbents. ${ }^{21}$ However, impertinent discard and landfill of some raw materials, such as bones waste, led to environmental pollution, and some other raw materials such as HAP, chitosan are expensive and with complicated regeneration. Therefore, materials waste made into adsorbents for fluoride removal from contaminated groundwater has become a significant direction to explore nowadays, especially in regions with limited resources.

With the acceleration of urbanization and an increasing population, the annual consumption of large amounts of meat in China results in a large amount of bone waste. Bone waste is calcined to obtain bone char, whose main inorganic component is HAP, $\mathrm{Ca}_{10}\left(\mathrm{PO}_{4}\right)_{6}(\mathrm{OH})_{2} \cdot{ }^{22} \mathrm{HAP}$, as an important inorganic material, has attracted significant attention in the last two decades due to its structure, ion-exchange capacity and adsorption affinity. ${ }^{23}$ HAP has been used as an adsorbent for the efficient and selective removal of fluoride from aqueous solution through adsorption and ion exchange. ${ }^{24}$ It was reported that bone waste had been the subject topic of a number of studies using it as fluoride adsorbent. For example, MedellinCastillo reported the fluoride removal performance of bone char made from cattle bones waste, which the adsorption capacity was 2.8 and 36 times greater than those of a commercial activated alumina and a commercial activated carbon. This study concluded that the fluoride adsorption on bone char was due to its HAP content. ${ }^{25}$ On the other hand, Rojas-Mayorga reported the optimization of a pyrolysis process at the temperatures of $700{ }^{\circ} \mathrm{C}$ for the synthesis of bone char. This study concluded that pyrolysis temperatures higher than $700{ }^{\circ} \mathrm{C}$ cause the dehydroxylation of the hydroxyapatite of bone char reducing its fluoride adsorption capacity. ${ }^{26}$ In other study, Medellin-Castillo determined the effects of solution $\mathrm{pH}$ on the adsorption of fluoride onto bone char, which the adsorption capacity drastically increased while decreasing the $\mathrm{pH}$ from 7.0 to $5.0 .^{23}$ It is obvious that the operating conditions for bone waste play an important role to determine the final adsorption capacities of the adsorbent. In general, the fluoride adsorption properties of commercial bones waste may be limited, and range from about 0.5 to $3.0 \mathrm{mg} \mathrm{g}^{-1} .^{10,25}$ Therefore, bone obtained from modified process may show better adsorption capacities. The fluoride ion is classified as a hard base, which has a strong affinity towards multivalent metal ions due to its high electro-negativity and small ionic size. ${ }^{27}$ Meanwhile, earth metal, such as lanthanum, classified as a hard acid, show a high chemical attraction to fluoride ions. ${ }^{28}$ In other words, it is expected that using lanthanum-modified bone waste (LBW) as an adsorbent can not only achieve the recycling of waste, but also can achieve excellent fluoride removal due to its synergistic effect.

In order to achieve bone waste recycling and enhance the efficiency of fluoride removal, a LBW composite was prepared and tested to remove fluoride from aqueous solution. The surface properties and morphology of the LBW composite were obtained by characterization analysis. The adsorption performance of fluoride ions on the LBW composite was evaluated by batch experiments. The adsorption behaviors of fluoride were analyzed by adsorption kinetic and isotherm models. The peculiarity and applicability of the LBW composite for defluoridation in actual contaminated groundwater were examined. Finally, by combining the aforementioned results, the possible mechanisms of fluoride adsorption are also proposed.

\section{Materials and methods}

\subsection{Chemicals}

All chemicals used in this study, including $\mathrm{NaF}, \mathrm{LaCl}_{3} \cdot n \mathrm{H}_{2} \mathrm{O}$, $\mathrm{NaOH}, \mathrm{HCl}, \mathrm{NaHCO}_{3}, \mathrm{Na}_{2} \mathrm{CO}_{3}, \mathrm{NaNO}_{3}, \mathrm{Na}_{2} \mathrm{SO}_{4}, \mathrm{Na}_{3} \mathrm{PO}_{4}, \mathrm{AgNO}_{3}$ and $\mathrm{Na}_{3} \mathrm{C}_{6} \mathrm{H}_{5} \mathrm{O}_{7} \cdot 2 \mathrm{H}_{2} \mathrm{O}$, were of analytical grade without the need for further purification and were purchased from Sinopharm Chemical Reagent Co., Ltd., (Shanghai, China). The fluoride stock solution $\left(100 \mathrm{mg} \mathrm{L}^{-1}\right)$ were prepared by adding $\mathrm{NaF}(0.2210 \mathrm{~g})$, which was dried at $105^{\circ} \mathrm{C}$ for $2 \mathrm{~h}$ prior to use, to deionized water $(1000 \mathrm{~mL})$. The test solutions were prepared by suitable dilution of the standard stock solution.

\subsection{Preparation of sodium form of bone waste}

The creatural bone wastes collected from local restaurants were dried in an oven at $100{ }^{\circ} \mathrm{C}$ for $3 \mathrm{~h}$ after cleanly removing surficial fat and meat pieces. The dried bones were crushed and further calcined at $500{ }^{\circ} \mathrm{C}$ for $4 \mathrm{~h}$. Bone particles with sizes between 75 and $165 \mu \mathrm{m}$ was selected after milling and sieving. A fullysaturated sodium form of bone waste (Na-BW) was used in the whole study due to its high ion-exchange capacity, promoting the composition between metal cations and bone waste particles. ${ }^{29,30}$ According to the mass ratio of $\mathrm{NaCl}$ to bones (1:5), the Na-BW was prepared by adding a $10 \mathrm{wt} \% \mathrm{NaCl}$ solution into a $10 \mathrm{wt} \%$ bone waste aqueous suspension. After $1 \mathrm{~h}$ of vigorous stirring at $70{ }^{\circ} \mathrm{C}$, the resulting suspension was kept for $24 \mathrm{~h}$ at room temperature $\left(25 \pm 2{ }^{\circ} \mathrm{C}\right)$. Then the solid and liquid parts were separated by centrifugation and washed with deionized water until no chloride was tested in the supernatant (detected with a $0.01 \mathrm{~mol} \mathrm{~L}^{-1} \mathrm{AgNO}_{3}$ solution). Finally, the filter cake was dried under $100{ }^{\circ} \mathrm{C}$ for $3 \mathrm{~h}$ to obtain the Na-BW.

\subsection{Preparation of LBW composite}

The LBW composite was prepared on the basis of the previous research ${ }^{31}$ with some modifications according to the following steps: (1) $5 \mathrm{~g}$ of $\mathrm{LaCl}_{3} \cdot n \mathrm{H}_{2} \mathrm{O}$ was dissolved in $100 \mathrm{~mL}$ of deionized water by ultrasonic dispersion for $5 \mathrm{~min}$. After $12 \mathrm{~h}$ of aging under $60{ }^{\circ} \mathrm{C}$, the solution was stabilized at room temperature $\left(25 \pm 2{ }^{\circ} \mathrm{C}\right.$ ) for $12 \mathrm{~h}$ to obtain solution $\mathrm{A}$; (2) a certain amount of $\mathrm{Na}-\mathrm{BW}$ (mass ratio of Na-BW to $\mathrm{LaCl}_{3} \cdot n \mathrm{H}_{2} \mathrm{O} 2: 1$ ) was added into $100 \mathrm{~mL}$ of deionized water under vigorous stirring for 10 min to obtain solution B; (3) solution A was dropped into solution B under strong stirring at a slow speed of $0.5 \mathrm{~mL} \mathrm{~s}^{-1}$, followed by stirring at room temperature $\left(25 \pm 2{ }^{\circ} \mathrm{C}\right)$ for $2 \mathrm{~h}$. Then, $0.2 \mathrm{~N} \mathrm{NaOH}$ solution was immersed into the system for $2 \mathrm{~h}$ to keep the $\mathrm{pH}$ of the mixture within a range of 5.0-6.0; (4) the precipitate was centrifuged and further dried completely. 
Finally, the prepared LBW composite was powdered and used for fluoride adsorption experiments.

\subsection{Characterization}

The lanthanum crystal structure present in the LBW was analyzed using X-ray diffraction (XRD) (DX-2700, Dangdong Fangyuan, China) equipped with $\mathrm{Cu} \mathrm{K} \alpha$ radiation $(\lambda=0.154056$ $\mathrm{nm}$ ), and the accelerating voltage and the applied current were held at $40 \mathrm{kV}$ and $30 \mathrm{~mA}$, respectively. The surface morphology of bone waste and LBW composite were observed using a scanning electron Microscope (SEM) (S4800, Hitachi, Japan). The specific surface area, pore volume and pore size distribution were determined by the Brunauer-Emmett-Teller (BET) theory, using $\mathrm{N}_{2}$ as the adsorption/desorption reagent at $77 \mathrm{~K}\left(-196^{\circ} \mathrm{C}\right)$ (ASAP2020, MICROMERITICS, USA). The zeta potentials of LBW before and after fluoride adsorption were measured using a Zetasizer analyzer (ZEN 3600, Malvern Instruments Ltd., U.K.). Fourier transform infrared (FTIR) spectra were recorded on a Fourier transform infrared spectrometer (TENSOR27, Bruker, Germany) with a resolution of $0.4 \mathrm{~cm}^{-1}$. The surface chemistry of LBW before and after fluoride adsorption were analyzed using X-ray photoelectron spectroscopy (XPS) (ESCALAB 250Xi, Thermo Scientific, USA) with a monochromatic Al K $\alpha$ X-ray source $(1486.6 \mathrm{eV})$.

\subsection{Adsorption experiments and analytical methods}

To investigate the ability of fluoride removal by the LBW from aqueous solutions, batch adsorption tests were carried out in detail. The solution $\mathrm{pH}$ was adjusted by $0.2 \mathrm{~N} \mathrm{HCl}$ or $\mathrm{NaOH}$. Unless otherwise stated, all the experiments were conducted by adding $1.0 \mathrm{~g}$ of adsorbent into a $250 \mathrm{~mL}$ polypropylene vessel containing $100 \mathrm{~mL}$ of $10 \mathrm{mg} \mathrm{L}^{-1} \mathrm{~F}^{-}$solution. The vessels were agitated at $200 \mathrm{rpm}$ in a thermostatic shaker at room temperature $\left(25 \pm 2{ }^{\circ} \mathrm{C}\right)$ for $24 \mathrm{~h}$ to attain the equilibrium. All adsorption experiments were carried out three times. Then, the aqueous solution was sampled at desired times and filtered through a $0.22 \mu \mathrm{m}$ cellulose acetate filter. The concentration of fluoride in solution was measured using a fluoride-ion-selective electrode (PF-1 Leici China). TISABI (total ionic strength adjustment buffer, $\mathrm{pH}$ 5-6) was added to the solution to protect the fluoride measurements from the interference of other ions.

The amounts of fluoride adsorbed per unit weight of LBW composite at time $t\left(q_{t}, \mathrm{mg} \mathrm{g}^{-1}\right)$ and at equilibrium $\left(q_{\mathrm{e}}, \mathrm{mg} \mathrm{g}^{-1}\right)$ were calculated using the following equations, respectively: ${ }^{32}$

$$
\begin{aligned}
& q_{t}=\frac{\left(C_{0}-C_{t}\right) V}{m} \\
& q_{\mathrm{e}}=\frac{\left(C_{0}-C_{\mathrm{e}}\right) V}{m}
\end{aligned}
$$

where $C_{0}\left(\mathrm{mg} \mathrm{L}^{-1}\right), C_{t}\left(\mathrm{mg} \mathrm{L}^{-1}\right)$ and $C_{\mathrm{e}}\left(\mathrm{mg} \mathrm{L}^{-1}\right)$ are the concentration of fluoride at the initial time, a given time $t$ and the equilibrium, respectively; $V(\mathrm{~L})$ is the volume of the aqueous solution; and $m(\mathrm{~g})$ is the dry mass of the adsorbent.

The effect of $\mathrm{pH}$ on the removal of fluoride was investigated by adjusting the initial $\mathrm{pH}$ of the fluoride solutions to 2.5-11.5.
The effect of co-existing oxygen anions was tested by adding different oxygen anions $\left(\mathrm{CO}_{3}{ }^{2-}, \mathrm{HCO}_{3}{ }^{-}, \mathrm{NO}_{3}{ }^{-}, \mathrm{SO}_{4}{ }^{2-}\right.$ and $\left.\mathrm{PO}_{4}{ }^{3-}\right)$ at different concentrations $\left(5,10,50\right.$ and $\left.100 \mathrm{mg} \mathrm{L}^{-1}\right)$. The kinetic studies were executed in $200 \mathrm{~mL}$ of fluoride solution $\left(10,30\right.$ and $\left.50 \mathrm{mg} \mathrm{L}^{-1}\right)$ with $2.0 \mathrm{~g}$ of LBW and a required amount of sample was collected at preset time intervals to determine the residual fluoride concentration. The isotherm studies were performed at different initial concentrations $\left(5-60 \mathrm{mg} \mathrm{L}^{-1}\right)$ at 25,35 and $45^{\circ} \mathrm{C}$.

\section{Results and discussion}

\subsection{Adsorbent characterization}

3.1.1. SEM and BET analysis. The SEM images $(50000 \times)$ of Na-BW and the LBW composite before and after fluoride adsorption are shown in Fig. 1. Unlike Na-BW, which had poor pores (Fig. 1a), LBW presented a more irregular surface and porous structure (Fig. 1b). This means that the addition of lanthanum could increase the specific surface area of the adsorbent and thereby provide more available adsorption sites. However, as illustrated in Fig. 1c, the pores of LBW became fewer and smaller after adsorption, indicating that LBW composite might be bonded by fluoride ions.

The specific surface area and pore size distribution of the adsorbent exert a significant effect on the intraparticle diffusion of fluoride ions. BET analysis indicates that the specific surface area, total pore volume and average pore diameter of the LBW composite were $85.4 \mathrm{~m}^{2} \mathrm{~g}^{-1}, 0.242 \mathrm{~cm}^{3} \mathrm{~g}^{-1}$ and $10.99 \mathrm{~nm}$, respectively. The $\mathrm{N}_{2}$ adsorption-desorption isotherm of LBW sample is shown in Fig. 1d. According to the International Union of Pure and Applied Chemistry (IUPAC) classification, ${ }^{33}$ the LBW adsorbent was of type IV with hysteresis hoops of type H3. The pore size distribution mainly concentrates in a range less than $21 \mathrm{~nm}$, revealing that the composite was a mesoporous material with a significantly large specific surface area.

3.1.2. XRD analysis. The XRD patterns of the bone waste and LBW composite are depicted in Fig. 2. By comparing with the Joint Committee on Powder Diffraction Standards (JCPDS) file, the characteristic peaks of Na-BW confirmed the presence of the calcium HAP at $2 \theta=25.9^{\circ}, 32^{\circ}$ and $39.8^{\circ}$, which showed efficient adsorbing-capacity for fluoride. ${ }^{10}$ However, these peaks were much less intensive or disappear in LBW, revealing a change of the original structure of bone waste after $\mathrm{LaCl}_{3}$ addition. The diffraction peaks at $2 \theta=15.6^{\circ}, 26^{\circ}, 27^{\circ}, 30.3^{\circ}$, $32^{\circ}, 39.6^{\circ}$ and $43.3^{\circ}$ could be ascribed to $\mathrm{La}(\mathrm{OH})_{3}$ and the peaks at $2 \theta=25^{\circ}, 29.5^{\circ}, 37.9^{\circ}, 54^{\circ}$ and $58^{\circ}$ were consistent with $\mathrm{La}_{2} \mathrm{O}_{3}$ or organic lanthanum (R-La-OH), according to the lanthanum crystallographic letters, as discussed in the literatures. ${ }^{34,35}$ Moreover, the peaks of the crystalline structure of lanthanum exhibited a weak intensity because of the low content of lanthanum in the LBW composite. Overall, the micro amount of La doped in LBW contributed to significant defluorination. ${ }^{28}$

3.1.3. FTIR analysis. The FTIR spectra of Na-BW, LBW before and after fluoride adsorption are compared in Fig. 3. The major characteristic bands for Na-BW are listed as follows: the peaks around $3455 \mathrm{~cm}^{-1}$ were the $-\mathrm{OH}$ bond stretching vibration modes of free water (surface-adsorbed water) and HAP., ${ }^{1,24}$ 

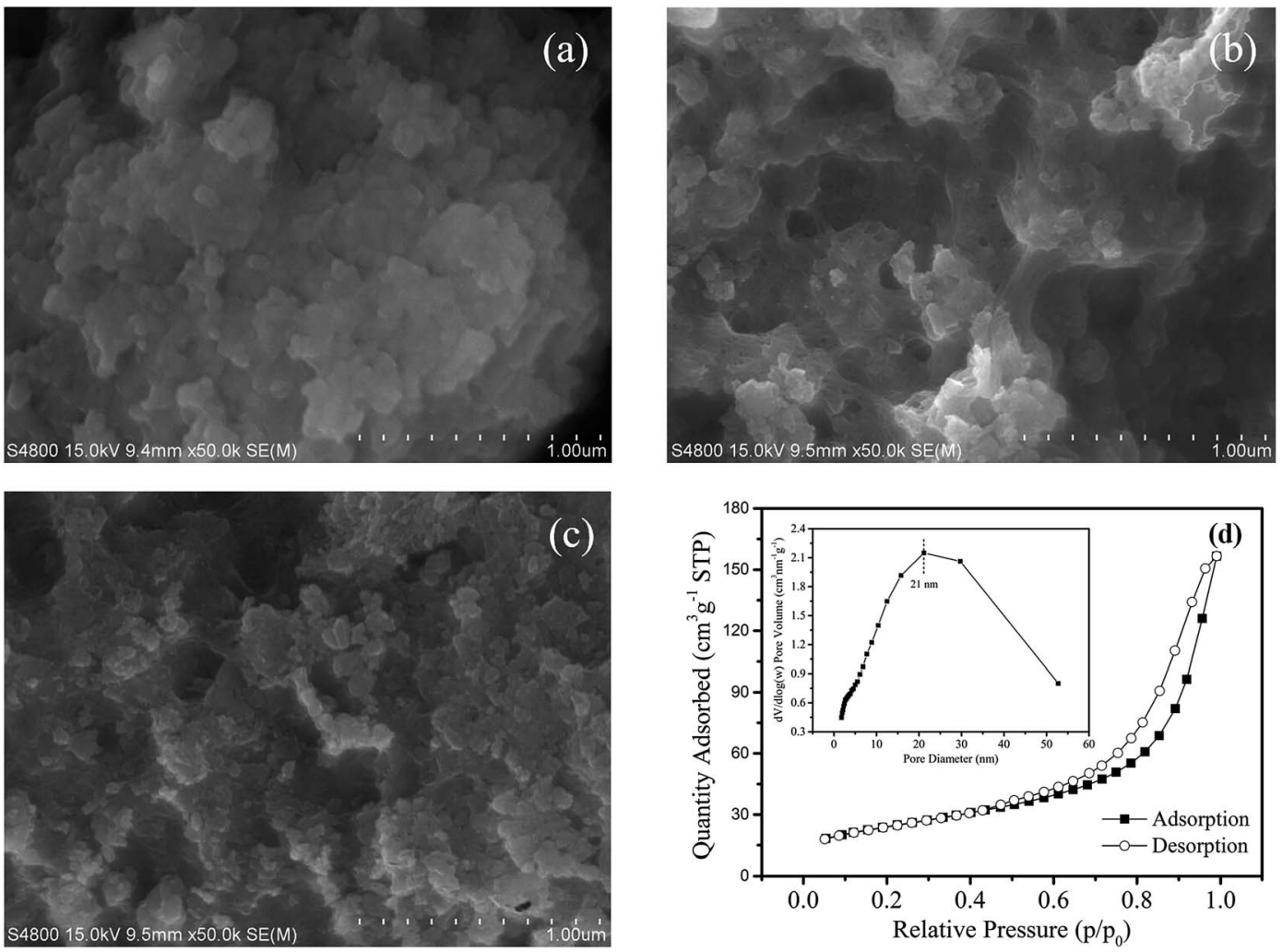

Fig. 1 SEM images of (a) Na-BW, (b) LBW composite before adsorption, (c) LBW composite after adsorption; (d) $\mathrm{N}_{2}$ adsorption-desorption isotherms and pore size distribution of LBW.

The peaks at 1635,1416 and $871 \mathrm{~cm}^{-1}$ were attributed to stretching vibration of $\mathrm{C}=\mathrm{O}$, $\mathrm{COO}-$ and $\mathrm{CO}_{3}{ }^{2-}, 1,26,36,37$ respectively. Moreover, the peak at $1045 \mathrm{~cm}^{-1}$ corresponded to the stretching vibration of $\mathrm{PO}_{4}{ }^{3-},{ }^{37}$ and the peaks at 569 and $663 \mathrm{~cm}^{-1}$ were the bending vibration of $\mathrm{P}-\mathrm{O} .{ }^{38}$ Compared to the Na-BW sample, the major characteristic bands for the LBW sample before fluoride adsorption exhibited no significant change in the modified process. However, the strong increasing intensity at $3443 \mathrm{~cm}^{-1}$ in the LBW sample before fluoride adsorption, which corresponded to $-\mathrm{OH}$ stretching vibration,

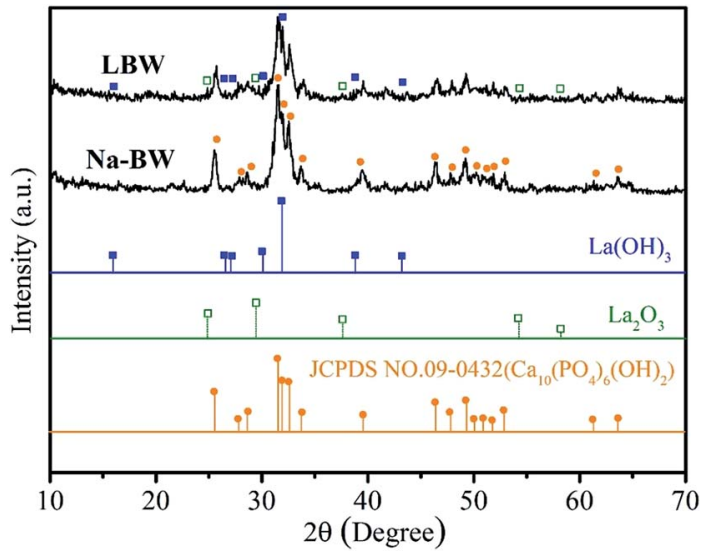

Fig. 2 XRD patterns of Na-BW and LBW. suggests the formation of lanthanum hydroxide $\left(\mathrm{La}(\mathrm{OH})_{3}\right)$ during the modification process due to the ion-exchange reaction between $\mathrm{Na}^{+}$and $\mathrm{La}^{3+} .{ }^{39}$ The introduction of lanthanum was beneficial for defluorination. After fluoride adsorption, the slight decrease in intensity at $3453 \mathrm{~cm}^{-1}$ and the occurrence of blue shift from 3443 to $3453 \mathrm{~cm}^{-1}$ explained the fact that fluoride might interact with the $-\mathrm{OH}$ groups present on $\mathrm{LBW}$ surface. ${ }^{1}$ Furthermore, the peak of $\mathrm{PO}_{4}{ }^{3-}$ shifted from 1035 to

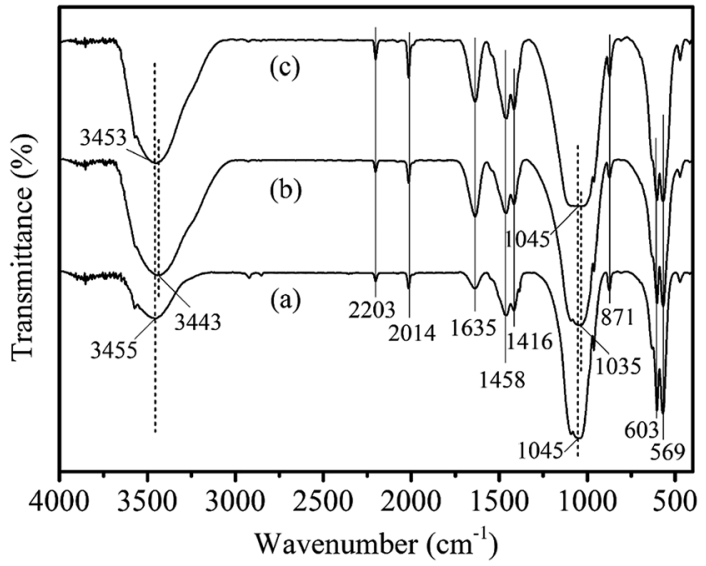

Fig. 3 FTIR spectra of Na-BW and LBW composite before and after fluoride adsorption: Na-BW (a), LBW composite (b), and fluoride adsorbed LBW composite (c). 
$1045 \mathrm{~cm}^{-1}$ and the slight decrease of intensity at 569 and $603 \mathrm{~cm}^{-1}$ of $\mathrm{P}-\mathrm{O}$ confirmed the hydroxyl groups on $\mathrm{PO}_{4}{ }^{3-}$ position $^{37,38}$ or the ligand exchange reaction between fluoride ion and hydroxyl group on the surface of the LBW. ${ }^{39}$

3.1.4. XPS analysis. The XPS spectra of LBW composite before and after fluoride adsorption were examined to gain insights into the adsorption mechanism. As shown in Fig. 4a, the XPS survey spectrum of the LBW composite before fluoride adsorption clearly confirmed the presence of C, O, Cl, P, La and $\mathrm{Ca}$. The occurrence of a new peak at $\sim 685 \mathrm{eV}$ in high resolution after fluoride removal was assigned to the $\mathrm{F}$ 1s spectrum, indicating that fluoride was bound to the adsorbents. ${ }^{\mathbf{2 4 , 4 0}}$ This result was further confirmed by the detailed $\mathrm{F}$ 1s spectrum in Fig. 4b. The F 1s photoelectron was resolved to two peaks located at 688.7 and $684.9 \mathrm{eV}$, which corresponded to inorganic fluoride attributed to metal $\mathrm{MF}_{n}$ and organic fluoride bonded to metal R-M-F (M: Ca or La), respectively.,40,41 As shown in Fig. 4c, the detail $\mathrm{O} 1 \mathrm{~s}$ spectrum was divided into three peaks, which were anion oxide $\left(\mathrm{O}^{2-}\right)$, hydroxyl bonded to metal (M-
$\mathrm{OH})$ and adsorbed water $\left(\mathrm{H}_{2} \mathrm{O}\right)$, respectively. ${ }^{24,37}$ It is clear that the area ratio of hydroxyl groups $(-\mathrm{OH})$ decreased from $33.7 \%$ to $20 \%$ after fluoride adsorption, which further indicated the supposition that fluoride was adsorbed on LBW via the exchange of fluoride ions with hydroxyl groups on the adsorbent surface. ${ }^{37,41}$ In addition, the area ratio of anion oxide $\left(\mathrm{O}^{2-}\right)$ increased from $36.8 \%$ to $57.8 \%$ after fluoride adsorption, indicating that amount of organic fluoride bonded to metal (R-M-F) formed after adsorption.

Fig. 4d exhibits the high resolution La $3 \mathrm{~d}$ region in the XPS spectrum of the LBW composite before and after fluoride adsorption. It shows that there were two sets of peaks in the La $3 \mathrm{~d}$ region due to spin-orbit interaction and each of these peaks has a doublet of comparable intensity. The binding energies of the primary La $3 \mathrm{~d}_{5 / 2}$ and La $3 \mathrm{~d}_{3 / 2}$ bands were at $835.9 \mathrm{eV}$ and $852.7 \mathrm{eV}$, respectively, and the corresponding satellites were located on their higher binding energy side at $839.2 \mathrm{eV}$ and $856.3 \mathrm{eV}$, respectively. ${ }^{42}$ The spin-orbit splitting of the primary La $3 \mathrm{~d}_{5 / 2}$ and La $3 \mathrm{~d}_{3 / 2}$ bonds was $16.8 \mathrm{eV}$. These satellite peaks
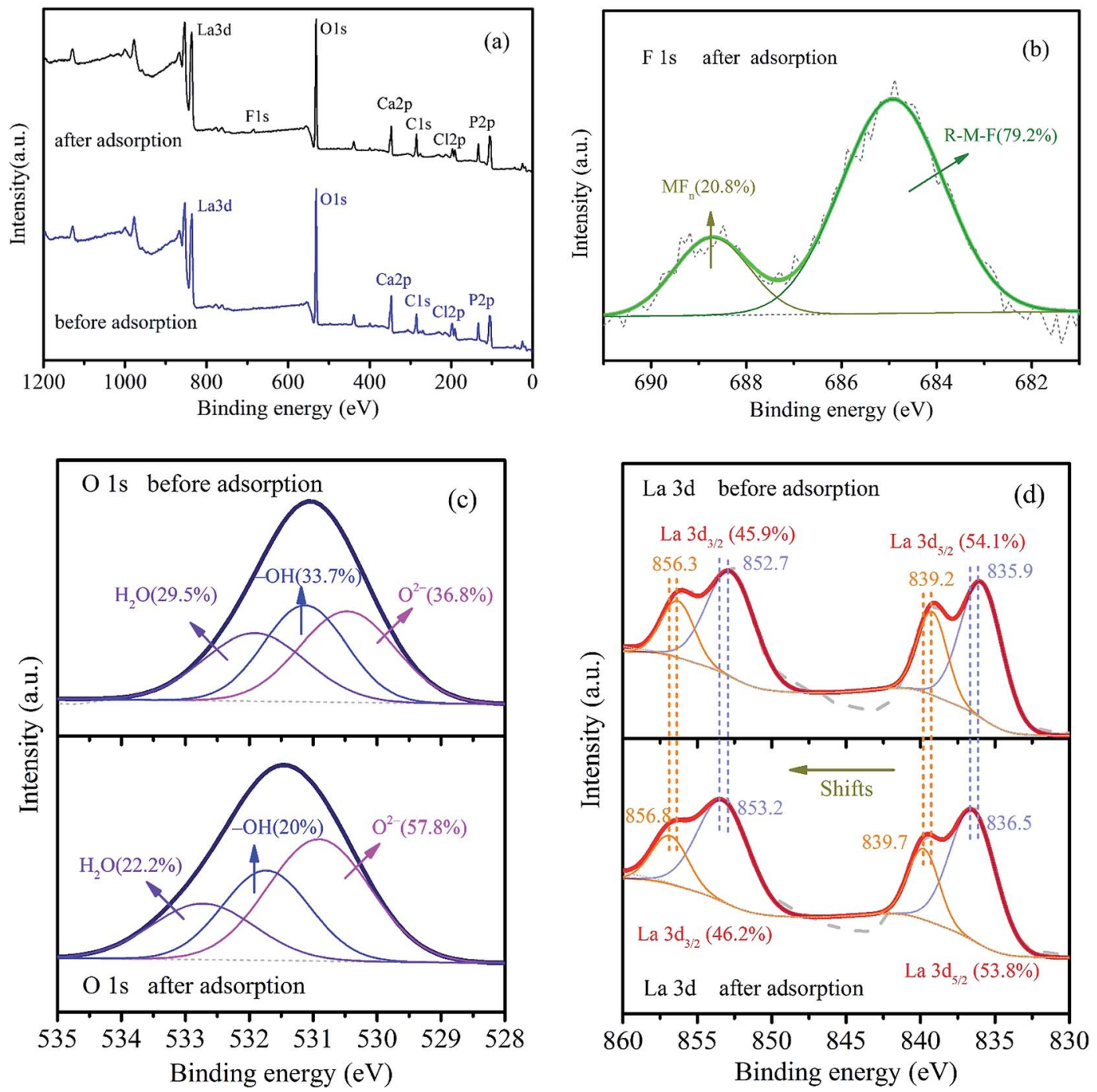

Fig. 4 (a) Wide-scan XPS spectra of LBW before and after fluoride adsorption, XPS spectra of (b) F 1s after fluoride adsorption, (c) O 1s and (d) La $3 d$ before and after fluoride adsorption. 
were observed due to the transfer of an electron from $\mathrm{O} 2 \mathrm{p}$ to the empty $4 \mathrm{f}$ shell of La, leading to the $3 \mathrm{~d}^{9} 4 \mathrm{f}^{1}$ final state. ${ }^{43}$ These results confirm the presence of $\mathrm{R}-\mathrm{La}-\mathrm{OH}, \mathrm{La}_{2} \mathrm{O}_{3}$ or $\mathrm{La}(\mathrm{OH})_{3}$. It is found that the binding energies of all peaks of La $3 \mathrm{~d}$ shifted to the higher binding energy side after fluoride adsorption, which was ascribed to the fact that the electronegativity of fluoride ions (3.98) was more than chloride ions (3.16). ${ }^{44}$ Therefore, ion exchange between $\mathrm{F}^{-}$and $\mathrm{Cl}^{-}$might be another approach for fluoride removal.

\subsection{Effect of $\mathbf{p H}$}

The $\mathrm{pH}$ of solution was a vital parameter affecting the chemical species of the solute and the surface properties of the adsorbent, such as surface charges. ${ }^{45}$ The effect of $\mathrm{pH}$ on fluoride adsorption and zeta potential of the surface of the LBW adsorbent before and after fluoride adsorption are shown in Fig. 5. In the present study, the $\mathrm{pH}$ of the point of zero charge $\left(\mathrm{pH}_{\mathrm{zpc}}\right)$ for the LBW composite was 11.4. This means that there are abundant positive charges on the surface of LBW complex when the $\mathrm{pH}$ is less than 11.4, which is favorable for the electrostatic attraction of negative fluoride ions. However, the $\mathrm{pH}_{\mathrm{zpc}}$ of the LBW composite has decreased from 11.4 to 6.5 after fluoride adsorption, suggesting that the negative fluoride ions neutralized some positive charges on the adsorbent surface. ${ }^{31}$ As shown in Fig. 5, there was no significant change in terms of fluoride removal efficiencies (exceeding 91\%) over a wide $\mathrm{pH}$ range of 2.5-10.0 (less than $\mathrm{pH}_{\mathrm{zpc}}$ ), indicating that electrostatic attraction might play an important role in fluoride removal. ${ }^{46}$ Nevertheless, the fluoride removal efficiency decreased obviously with further increasing of the initial $\mathrm{pH}(\mathrm{pH}>10)$, and the fluoride removal efficiency decreased to $81.9 \%$ at a $\mathrm{pH}$ of 11.5 . The decrease in fluoride adsorption is probably ascribed to the following facts: (i) the negatively charged adsorbent surface failed to adsorb fluoride ions due to electrostatic repulsion; (ii) abundant hydroxide ions led to a competition of fluoride ions for adsorption sites. ${ }^{47}$ Furthermore, the final $\mathrm{pH}$ of solution was located between 5.8 and 7.0 after fluoride adsorption, suggesting that the LBW composite had a certain buffer capacity. This might be attributed to the presence of carbonate in the LBW composite, which could consume $\mathrm{H}^{+}$in acid condition. While

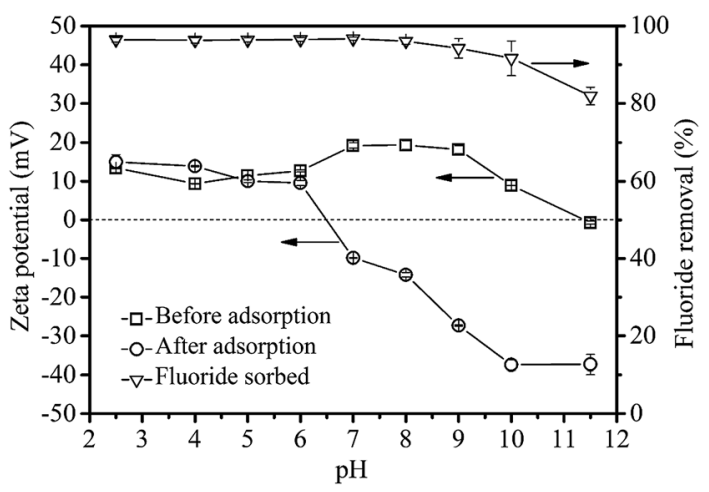

Fig. 5 Effect of $\mathrm{pH}$ on fluoride adsorption and zeta potential of the surface of the LBW adsorbent before and after fluoride adsorption. the ion exchange between $\mathrm{Cl}^{-}$on the LBW surface and $\mathrm{OH}^{-}$in aqueous solution could decrease the solution $\mathrm{pH}$ at alkaline condition. ${ }^{45}$ In conclusion, LBW composite showed great water stability and could maintain high efficiency for fluoride removal in a wide $\mathrm{pH}$ range.

\subsection{Effect of co-existing oxygen anions}

Some co-existing oxygen anions exist in groundwater may compete with fluoride ions for adsorption sites, leading to a decrease in fluoride removal efficiency. ${ }^{48,49}$ The effects of coexisting oxygen anions that are typically present in groundwater on fluoride removal are shown in Fig. 6, and the ion concentrations and $\mathrm{pH}$ values of solution before and after fluoride adsorption for co-existing oxygen anions are shown in Table 1. It was found that the concentrations of nitrate, sulfate and phosphate reduced to different degrees (Table 1), indicating that these anions were also removed during the fluoride adsorption, especially for phosphate removal. The competitive adsorption between $\mathrm{PO}_{4}{ }^{3-}$ with $\mathrm{F}^{-}$appeared to be evident. This is because that $\mathrm{La}^{3+}$ in the adsorbent had high affinity capacity for $\mathrm{PO}_{4}{ }^{3-}$. However, the occurrence of nitrate $\left(\mathrm{NO}_{3}{ }^{-}\right)$, phosphate $\left(\mathrm{PO}_{4}{ }^{3-}\right)$, sulfate $\left(\mathrm{SO}_{4}{ }^{2-}\right)$, bicarbonate $\left(\mathrm{HCO}_{3}{ }^{-}\right)$had hardly any adverse effects on fluoride removal in the range of 0 $100 \mathrm{mg} \mathrm{L^{-1 }}$ (Fig. 6), which might be a result of the large amounts of available adsorption sites on the adsorbent and the LBW composite has good affinity for fluoride. ${ }^{31}$ The $\mathrm{pH}$ values of solution before and after fluoride adsorption were less than $\mathrm{pH}_{\mathrm{zpc}}$, and it was also proving that these anions were adsorbed due to electrostatic attraction and the adsorption ability gradually enhanced with the increase in charge $\left(\mathrm{NO}_{3}{ }^{-}<\mathrm{SO}_{4}{ }^{2-}<\right.$ $\left.\mathrm{PO}_{4}{ }^{3-}\right) .{ }^{46}$ In addition, carbonate $\left(\mathrm{CO}_{3}{ }^{2-}\right)$ showed little effect on fluoride removal at low concentrations, but had a relatively obvious impact at high concentrations. This phenomenon was explained by the following facts: (i) it was considered that $\mathrm{La}^{3+}$ had good coordination ability for $\mathrm{F}^{-}$and $\mathrm{OH}^{-}$. Thus, the $\mathrm{pH}$ of solution significantly increased due to $\mathrm{CO}_{3}{ }^{2-}$ hydrolysis at high

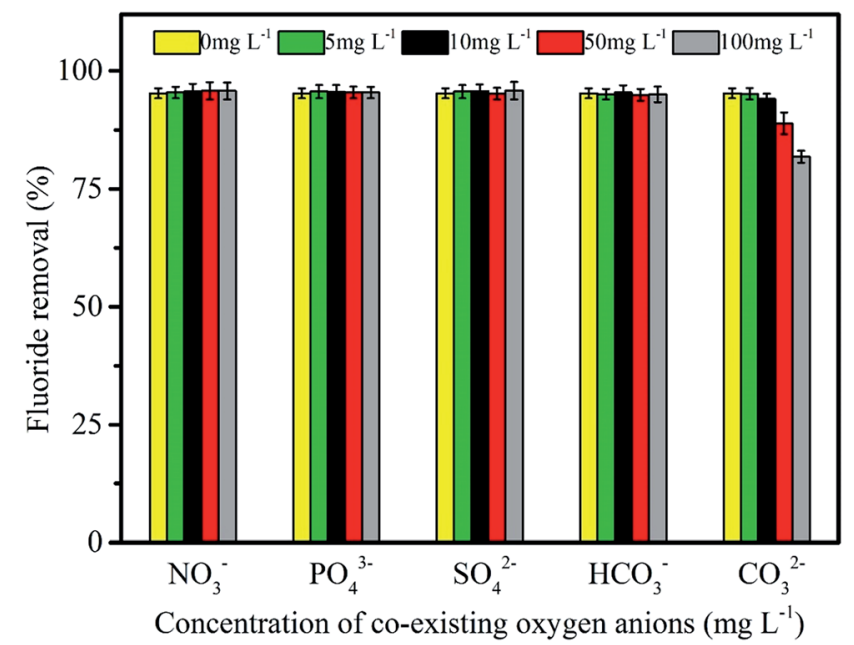

Fig. 6 Effect of co-existing oxygen anions on fluoride removal efficiency. 
Table 1 The changes in concentration and solution $\mathrm{pH}$ before and after fluoride adsorption for co-existing oxygen anions ${ }^{a}$

\begin{tabular}{|c|c|c|c|c|}
\hline \multirow[b]{2}{*}{ Oxygen anions } & \multicolumn{2}{|c|}{ Concentration $\left(\mathrm{mg} \mathrm{L}^{-1}\right)$} & \multicolumn{2}{|l|}{$\mathrm{pH}$} \\
\hline & Before adsorption & After adsorption & Before adsorption & After adsorption \\
\hline \multirow{3}{*}{$\mathrm{HCO}_{3}{ }^{-}$} & 10 & Nil & 7.28 & 5.92 \\
\hline & 50 & 16.25 & 7.45 & 6.17 \\
\hline & 100 & 30.69 & 7.78 & 6.31 \\
\hline & 50 & Nil & 7.51 & 6.02 \\
\hline & 100 & 0.242 & 7.37 & 6.03 \\
\hline \multirow[t]{4}{*}{$\mathrm{NO}_{3}^{-}$} & 5 & 4.89 & 8.47 & 5.90 \\
\hline & 10 & 9.92 & 8.38 & 5.97 \\
\hline & 50 & 49.00 & 8.07 & 5.89 \\
\hline & 100 & 98.91 & 7.29 & 5.89 \\
\hline \multirow[t]{4}{*}{$\mathrm{CO}_{3}{ }^{2-}$} & 5 & Nil & 7.65 & 6.04 \\
\hline & 10 & Nil & 8.08 & 6.11 \\
\hline & 50 & Nil & 9.85 & 6.39 \\
\hline & 100 & Nil & 9.99 & 6.70 \\
\hline
\end{tabular}

concentration, and then abundant $\mathrm{OH}^{-}$ions easily associated with $\mathrm{La}^{3+}$ forming strong surface complex and reducing surface potential. (ii) $\mathrm{OH}^{-}$ions produced from $\mathrm{CO}_{3}{ }^{2-}$ hydrolysis led to increased hindrance to the diffusion of fluoride ions. ${ }^{50}$ Typical concentration of $\mathrm{CO}_{3}{ }^{2-}$ in natural groundwater were much lower than that of other co-existing anions. Therefore, the interference of $\mathrm{CO}_{3}{ }^{2-}$ in natural environments could be negligible. Moreover, the final $\mathrm{pH}$ values of solution after fluoride adsorption for these anions concentrated in the range of 5.86.7 , which further indicates that the LBW composite had a good buffer capacity. ${ }^{45}$

\subsection{Kinetic studies}

In order to further understand the mechanisms of fluoride adsorption on the LBW composite, the experimental data are fitted with the pseudo-first-order (PFO) and pseudo-secondorder (PSO) kinetic models. ${ }^{1}$ The PFO and PSO kinetic models are expressed as:

$$
\begin{aligned}
& q_{t}=q_{\mathrm{e}}\left[1-\exp \left(-k_{1} t\right)\right] \\
& q_{t}=q_{\mathrm{e}}\left(1-\frac{1}{1+q_{\mathrm{e}} k_{2} t}\right)
\end{aligned}
$$

where $k_{1}\left(\mathrm{~min}^{-1}\right)$ and $k_{2}\left(\mathrm{~g} \mathrm{mg}^{-1} \mathrm{~min}^{-1}\right)$ are the rate constants of PFO and PSO, respectively, and $t(\mathrm{~min})$ is the adsorption time.

The amount of fluoride uptake with time at different concentrations is depicted in Fig. 7a. The adsorption process was extremely rapid. The adsorption reached to equilibrium within $5 \mathrm{~min}$ at a low fluoride concentration of $10 \mathrm{mg} \mathrm{L}^{-1}$, and the adsorption capacity remained essentially unchanged after $20 \mathrm{~min}$ at high fluoride concentration of $50 \mathrm{mg} \mathrm{L}^{-1}$. This means that the times required to reach equilibrium lengthened with the increasing of initial fluoride concentration. The kinetic parameters obtained from the PFO and PSO are shown in Table 2. It can be clearly seen that the rate constants provided by PFO and PSO vary with initial fluoride concentration, suggesting that $k_{1}$ and $k_{2}$ were the observed rate constants of the overall adsorption reaction rather than the intrinsic rate constants. The values of $k_{1}$ and $k_{2}$ decreased with increasing initial fluoride concentration, further suggesting that the reaction was faster at lower initial concentrations. Compared with PFO, the predicted values provided by PSO were more close to the experimental values, and PSO had lower RSS, $\chi^{2}$ values and higher Adj. $R^{2}$ value, indicating that fluoride adsorption on the LBW composite followed the PSO kinetic models well. These results indicate that fluoride adsorption on the LBW adsorbent was typical of a chemisorption process involving valence forces through sharing or the exchange of electrons between fluoride ions and LBW adsorbent. ${ }^{51}$ Furthermore, the adsorption rate was normally dependent upon the number of available adsorption sites on the adsorbent surface and eventually controlled by the attachment of fluoride ions on the surface. ${ }^{39}$

Moreover, it has been reported that the adsorption kinetics at the solid/solution interface with different types of surface sites and with different adsorption affinities could be also described by the fractal-like approach. ${ }^{52}$ The nonlinear forms of fractal-like pseudo-first-order (F-L PFO) and fractal-like pseudosecond-order (F-L PSO) rate equations are given as:

$$
q_{t}=q_{\mathrm{e}}\left[1-\exp \left(-\frac{k_{1}^{0}}{1-h} t^{(1-h)}\right)\right]
$$



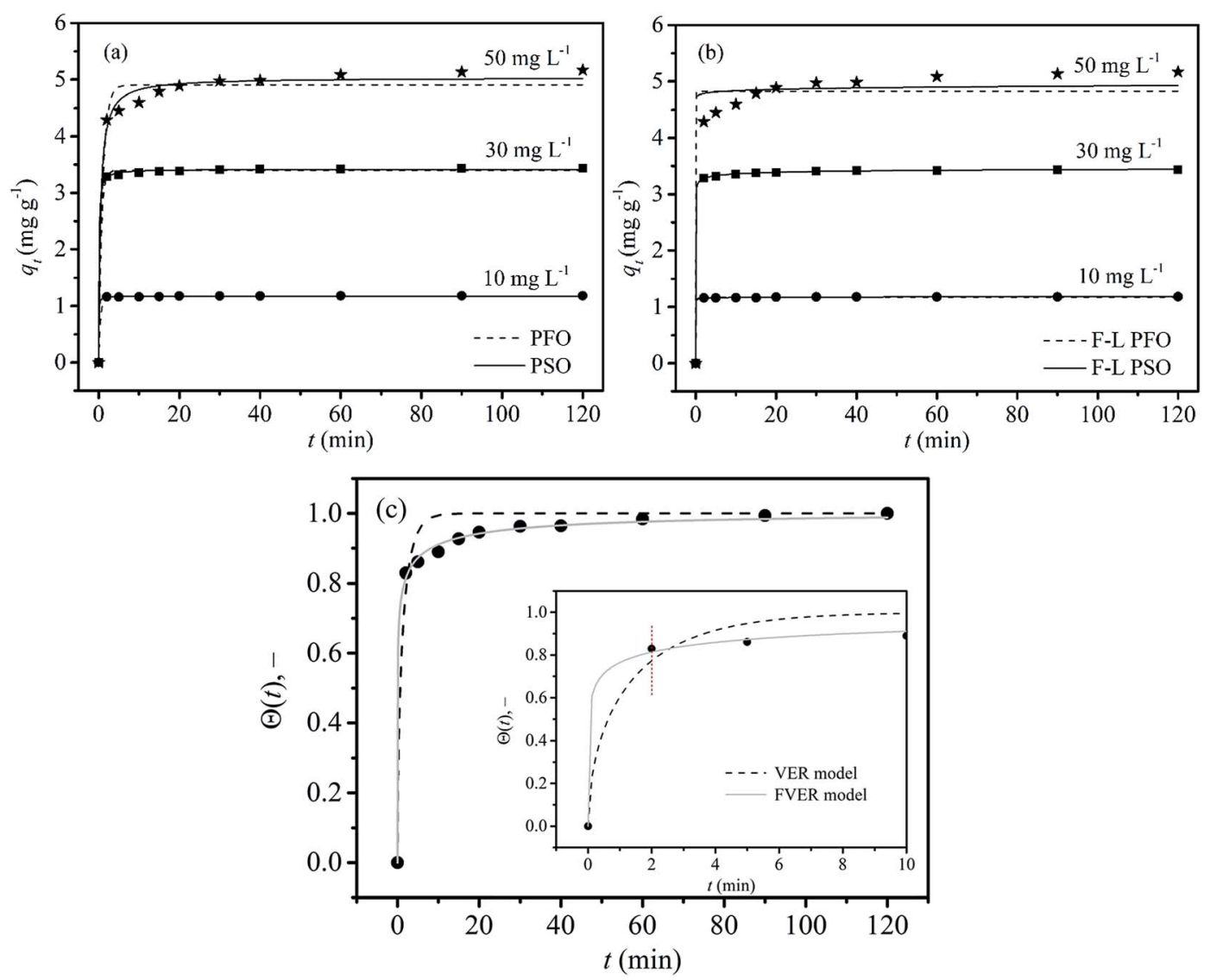

Fig. 7 Kinetic studies of fluoride removal by LBW: (a) PFO (the dash line), PSO (the solid line); (b) F-L PFO (the dash line), F-L PSO (the solid line); (c) VER (the dash line), FVER (the gray solid line), $\left(C_{0}=50 \mathrm{mg} \mathrm{L}^{-1}, m=10 \mathrm{~g}, \mathrm{~V}=100 \mathrm{~mL}\right.$ ).

$$
q_{t}=q_{\mathrm{e}}\left[1-\left(1-\frac{q_{\mathrm{e}} k_{2}^{0}}{1-h} t^{(1-h)}\right)^{-1}\right]
$$

where $k_{1}^{0}\left(\min ^{-1}\right)$ and $k_{2}^{0}\left(\mathrm{~g} \mathrm{mg}^{-1} \min ^{-1}\right)$ are the F-L PFO and F-L PSO rate constants, respectively, and $h$ is the fractal exponent.

The curve fit of the F-L PFO and F-L PSO rate equations is described in Fig. $7 \mathrm{~b}$ and their kinetic parameters are also listed in Table 2. Fluoride adsorption at different concentrations on LBW adsorbent was very rapid in the initial phase, followed by a short stage until adsorption equilibrium was reached. This result was consistent with that from PFO and PSO kinetic models. It is evident from Table 2 that the F-L PSO provided a satisfactory fitting with a high Adj. $R^{2}$ value and low RSS and $\chi^{2}$ values compared with the F-L PFO. This means that fluoride adsorption on the LBW composite also followed the F-L PSO kinetic models well. In addition, the rate constants predicted by the F-L PSO slightly vary at different concentrations compared with the PSO. This result supports the finding that the rate constant of the PFO and PSO were time dependent parameters.

In order to providing a further contribution in illustrating the effect of the adsorbent structural properties on the temporal variation of the intraparticle diffusion coefficient during adsorption of micropollutants, the nonlinear forms of the diffusive Vermeulen model (VER) and the fractal-like Vermeulen model (FVER) equations are given as: ${ }^{53}$

$$
\begin{gathered}
\Theta(t)=\sqrt{1-\exp \left(-\frac{4 \pi^{2} \mathcal{D}_{\mathrm{p}}}{d_{\mathrm{s}}{ }^{2}} t\right)} \\
\Theta(t)=\sqrt{1-\exp \left(-\frac{4 \pi^{2} \mathcal{D}_{\mathrm{p}}^{0}}{d_{\mathrm{s}}{ }^{2}} t^{(1-h)}\right)}
\end{gathered}
$$

where $\Theta$ and $d_{\mathrm{s}}(\mu \mathrm{m})$ are the surface coverage degree with respect to equilibrium and the Sauter particle diameter, respectively, and $\mathcal{D}_{\mathrm{p}}\left(\mathrm{m}^{2} \min ^{-1}\right)$ and $\mathcal{D}_{\mathrm{p}}^{0}\left(\mathrm{~m}^{2} \min ^{-(1-h)}\right)$ are the intraparticle diffusivity and the fractal diffusion kinetic constant, respectively.

A comparison of the kinetic adsorption profiles at high fluoride concentration of $50 \mathrm{mg} \mathrm{L^{-1 }}$ obtained from VER and FVER models is described in Fig. 7c. The main kinetic parameters are listed in Table 3. It can be found that the FVER model provided a more accurate prediction of the kinetic adsorption data to comparing with the VER one because of lower values of the HYBRID error function and higher values of the $\operatorname{Adj} . R^{2}$ $(>0.99)$. When the VER and FVER models are observed for $t>$ $1 \mathrm{~min}$, the VER model underestimates the adsorption data for shorter times. For example, $\Theta(t)$ at $t=2$ min equals 0.83 from experiments while it is 0.82 and 0.79 for the FVER and VER models, respectively. Therefore, the FVER model has been able to provide a well match with the experimental data in the whole 
Table 2 Kinetic parameters obtained from PFO, PSO, F-L PFO and F-L PSO

\begin{tabular}{|c|c|c|c|c|c|c|c|}
\hline Concentration $\left(\mathrm{mg} \mathrm{L}^{-1}\right)$ & \multicolumn{3}{|l|}{$\mathrm{PFO}$} & & RSS & $\chi^{2}$ & Adj. $R^{2}$ \\
\hline 30 & 3.44 & 3.40 & 1.70 & & $1.21 \times 10^{-2}$ & $1.34 \times 10^{-3}$ & 0.9987 \\
\hline 50 & 5.15 & 4.91 & 0.99 & & 0.45 & $5.03 \times 10^{-2}$ & 0.9772 \\
\hline 10 & 1.18 & 1.18 & 23.66 & & $3.44 \times 10^{-4}$ & $3.82 \times 10^{-5}$ & 0.9997 \\
\hline 30 & 3.44 & 3.42 & 3.10 & & $4.05 \times 10^{-3}$ & $4.50 \times 10^{-4}$ & 0.9996 \\
\hline \multirow[t]{2}{*}{50} & 5.15 & 5.03 & 0.45 & & 0.17 & $1.84 \times 10^{-2}$ & 0.9916 \\
\hline & \multicolumn{4}{|l|}{ F-L PFO } & RSS & $\chi^{2}$ & Adj. $R^{2}$ \\
\hline 30 & 3.44 & 3.50 & 0.24 & 0.91 & $2.38 \times 10^{-4}$ & $2.97 \times 10^{-5}$ & 0.9999 \\
\hline \multirow[t]{2}{*}{50} & 5.15 & 4.83 & 0.10 & 1.00 & 0.81 & 0.10 & 0.9539 \\
\hline & \multicolumn{4}{|l|}{ F-L PSO } & & & \\
\hline Concentration $\left(\mathrm{mg} \mathrm{L}^{-1}\right)$ & $q_{\exp }\left(\mathrm{mg} \mathrm{g}^{-1}\right)$ & $q_{\text {cal }}\left(\mathrm{mg} \mathrm{g}^{-1}\right)$ & $k_{2}^{0}\left(\mathrm{~g} \mathrm{mg}^{-1} \min ^{-1}\right)$ & $h$ & RSS & $\chi^{2}$ & Adj. $R^{2}$ \\
\hline 10 & 1.18 & 1.07 & 0.66 & 1.05 & $1.18 \times 10^{-4}$ & $1.48 \times 10^{-5}$ & 0.9999 \\
\hline 30 & 3.44 & 3.55 & 0.67 & 0.77 & $2.58 \times 10^{-4}$ & $3.23 \times 10^{-4}$ & 0.9999 \\
\hline 50 & 5.15 & 4.46 & 0.28 & 1.08 & 0.60 & $7.5 \times 10^{-2}$ & 0.9658 \\
\hline
\end{tabular}

time range. Especially in the short time at initial reaction stage of fluoride removal, the FVER model has proved that the adsorbent has a larger surface coverage degree with respect to equilibrium at initial times during adsorption of fluoride. However, the VER model has an undervaluation on the degree.

\subsection{Equilibrium studies}

Adsorption isotherms reflect the distribution of adsorbate molecules between solid and solution phases at equilibrium under the given conditions. The mathematical analyses of the process offered the information about adsorption capacity, as well as the surface properties and affinity of the adsorbent, contributing to insights into adsorption mechanisms and the optimization of process design. ${ }^{51}$ The Langmuir, ${ }^{2}$ Freundlich ${ }^{6}$ and two-site Langmuir ${ }^{48}$ isotherm models are employed to analyze equilibrium data of fluoride removal by the LBW adsorbent at different temperature, which are expressed as:

$$
\begin{gathered}
q_{\mathrm{e}}=\frac{Q_{\max } K_{\mathrm{L}} C_{\mathrm{e}}}{1+K_{\mathrm{L}} C_{\mathrm{e}}} \\
q_{\mathrm{e}}=K_{\mathrm{F}} C_{\mathrm{e}}{ }^{1 / n} \\
q_{\mathrm{e}}=\frac{Q_{1} K_{1} C_{\mathrm{e}}}{1+K_{1} C_{\mathrm{e}}}+\frac{Q_{2} K_{2} C_{\mathrm{e}}}{1+K_{2} C_{\mathrm{e}}}
\end{gathered}
$$

where $Q_{\max }\left(\mathrm{mg} \mathrm{g}^{-1}\right)$ is the maximum adsorption capacity, $K_{\mathrm{L}}\left(\mathrm{L} \mathrm{mg}^{-1}\right)$ and $K_{\mathrm{F}}\left(\left(\mathrm{mg} \mathrm{g}^{-1}\right)\left(\mathrm{L} \mathrm{mg}^{-1}\right)^{1 / n}\right)$ are the Langmuir and Freundlich constants, respectively, $n$ is an empirical parameter, $Q_{1}\left(\mathrm{mg} \mathrm{g}^{-1}\right)$ and $Q_{2}\left(\mathrm{mg} \mathrm{g}^{-1}\right)$ are the maximum adsorption capacity of the high and low bonding energy sites $\left(Q_{\max }=Q_{1}+\right.$ $\left.Q_{2}\right)$ and $K_{1}\left(\mathrm{~L} \mathrm{mg}^{-1}\right)$ and $K_{2}\left(\mathrm{~L} \mathrm{mg}^{-1}\right)$ are the corresponding affinity coefficients, respectively.

The isotherm plots of fluoride adsorption on the LBW composite were described in Fig. 8, and the obtained isotherm parameters from Langmuir, Freundlich and two-site Langmuir models are displayed in Table 4. The shape of the general

\begin{tabular}{|c|c|c|c|c|c|c|}
\hline \multirow{2}{*}{$\frac{\text { VER }}{\mathcal{D}_{\mathrm{p}}\left(\mathrm{m}^{2} \mathrm{~min}^{-1}\right)}$} & \multirow[b]{2}{*}{ HYBRID } & \multirow[b]{2}{*}{ Adj. $R^{2}$} & \multicolumn{2}{|l|}{ FVER } & \multirow[b]{2}{*}{ HYBRID } & \multirow[b]{2}{*}{ Adj. $R^{2}$} \\
\hline & & & $\mathcal{D}_{\mathrm{p}}^{0}\left(\mathrm{~m}^{2} \min ^{-(1-h)}\right)$ & $h$ & & \\
\hline
\end{tabular}
isotherm plot of $C_{\mathrm{e}}$ against $q_{\mathrm{e}}$ gave an indication of whether the

Table 3 Kinetic parameters obtained from canonical and fractal-like Vermeulen models. $\left(C_{0}=50 \mathrm{mg} \mathrm{L}^{-1}, \mathrm{~m}=10 \mathrm{~g}, V=100 \mathrm{~mL}\right)$ 

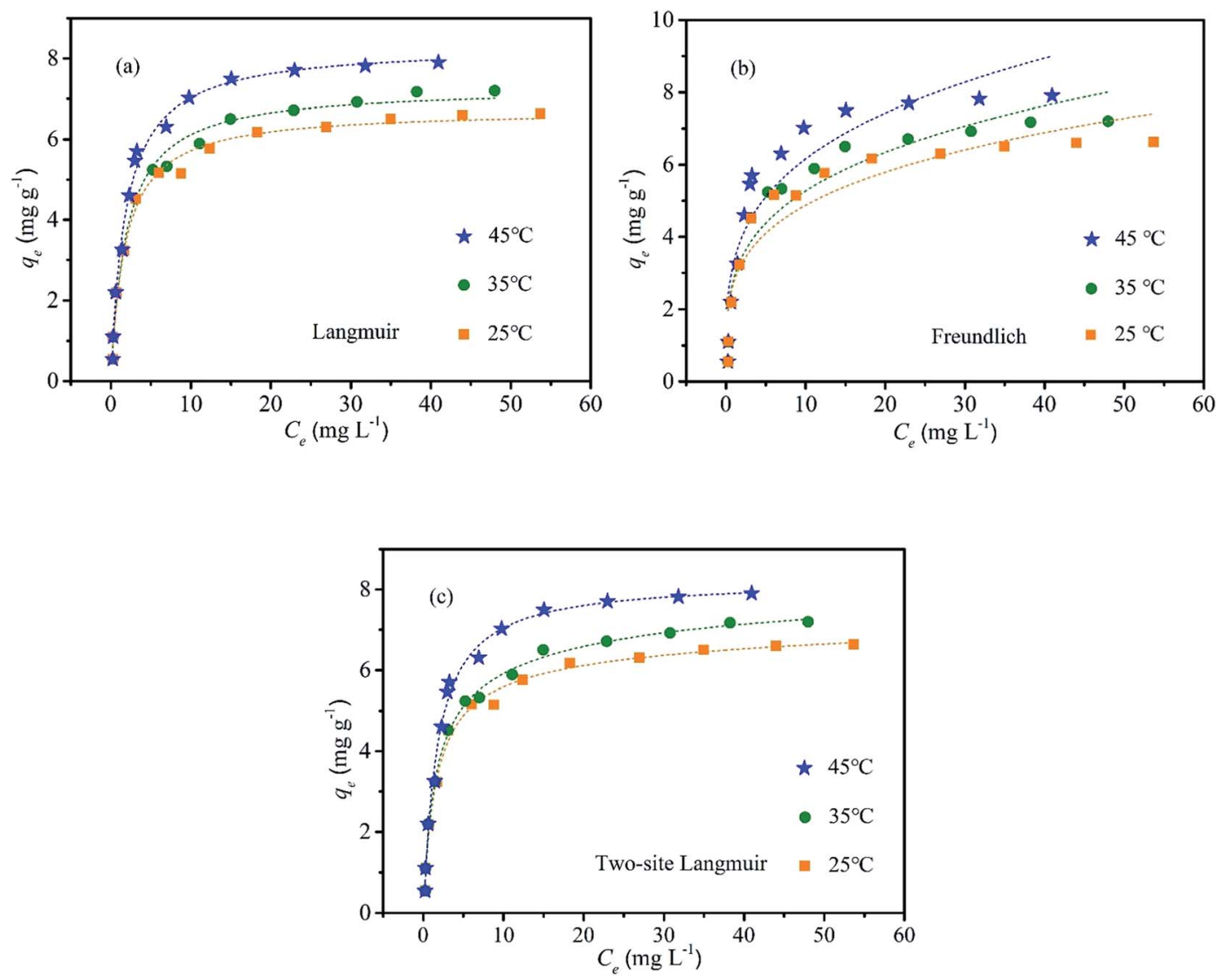

Fig. 8 Isotherm studies of fluoride removal by LBW at different temperature: (a) Langmuir; (b) Freundlich; (c) two-stie Langmuir.

adsorption was favorable or unfavorable. ${ }^{46}$ It is described that adsorption capacity increased with the temperature raising from 25 to $45^{\circ} \mathrm{C}$ in Fig. 8, suggesting that this reaction process was an endothermic reaction, and elevating temperature was favorable for fluoride adsorption. ${ }^{39}$ The equilibrium parameter $R_{\mathrm{L}}$, which is defined as $R_{\mathrm{L}}=1 /\left(1+b C_{0}\right)$, where $b$ is the Langmuir constant and $C_{0}$ is the initial concentration of fluoride. The $R_{\mathrm{L}}$ value indicated the shape of the isotherm, and in the range of $0<R_{\mathrm{L}}<1$ reflected the favorable adsorption process. ${ }^{54}$ The $R_{\mathrm{L}}$ value for the adsorption of fluoride on different adsorbents at initial concentration of $5 \mathrm{mg} \mathrm{L}^{-1}$ (lowest concentration studied) and $120 \mathrm{mg} \mathrm{L}^{-1}$ (highest concentration studied) were listed in Table 5. This indicated the fact that the adsorption process was very favorable and the adsorbent had a good potential for fluoride removal. ${ }^{55}$

Compared with the Freundlich model, the results in Table 4 showed that the Langmuir isotherm model fitted the experiment data well according to the smaller RSS and $\chi^{2}$ values and larger Adj. $R^{2}$ value. This indicated that the reaction was monolayer adsorption on the structurally homogeneous surface

Table 4 Isotherm parameters obtained from Langmuir, Freundlich and two-site Langmuir models

\begin{tabular}{|c|c|c|c|c|c|c|c|c|c|c|c|}
\hline $\begin{array}{l}\text { Temperature } \\
\left({ }^{\circ} \mathrm{C}\right)\end{array}$ & \multicolumn{2}{|l|}{ Langmuir } & RSS & $\chi^{2}$ & Adj. $R^{2}$ & \multicolumn{3}{|c|}{ Freundlich } & RSS & $\chi^{2}$ & Adj. $R^{2}$ \\
\hline 35 & 7.29 & 0.52 & 0.65 & 0.059 & 0.9891 & 2.86 & & 3.76 & 5.87 & 0.53 & 0.9016 \\
\hline 45 & 8.32 & 0.54 & 0.66 & 0.060 & 0.9912 & 3.31 & & 3.72 & 11.01 & 1.00 & 0.8538 \\
\hline 25 & 7.53 & 6.20 & & 1.33 & & 0.67 & 0.02 & 0.40 & & 0.044 & 0.9904 \\
\hline 35 & 8.19 & 6.06 & & 2.13 & & 0.74 & 0.04 & 0.34 & & 0.038 & 0.9930 \\
\hline 45 & 8.96 & 8.60 & & 0.36 & & 0.62 & 0.01 & 0.56 & & 0.062 & 0.9910 \\
\hline
\end{tabular}


Table 5 Equilibrium parameter $R_{\mathrm{L}}$ for adsorption of fluoride at different temperature

\begin{tabular}{lll}
\hline & \multicolumn{2}{l}{ Equilibrium parameter $\left(R_{\mathrm{L}}\right)$} \\
\cline { 2 - 3 } $\begin{array}{l}\text { Temperature } \\
\left({ }^{\circ} \mathrm{C}\right)\end{array}$ & $\begin{array}{l}\text { Initial fluoride } \\
\text { concentration } 5 \mathrm{mg} \mathrm{L}^{-1}\end{array}$ & $\begin{array}{l}\text { Initial fluoride } \\
\text { concentration } 120 \mathrm{mg} \mathrm{L}^{-1}\end{array}$ \\
\hline 25 & 0.2632 & 0.0147 \\
35 & 0.2778 & 0.0158 \\
45 & 0.2703 & 0.0152 \\
\hline
\end{tabular}

of the LBW adsorbent in the fluoride removal process. ${ }^{26}$ The predicted maximum adsorption capacity of fluoride was $8.32 \mathrm{mg} \mathrm{g}^{-1}$ at the $\mathrm{pH}$ of 7.0 and the temperature of $45^{\circ} \mathrm{C}$. The two-site Langmuir model was also suitable for describing fluoride adsorption on the LBW adsorbent due to its lower RSS and higher Adj. $R^{2}$ value at different temperature, suggesting that there might be two types of active sites with different binding energies on the adsorbent surface. Moreover, $Q_{1}>Q_{2}$ suggests that most of the adsorption sites could be characterized as high affinity sites and $K_{1}>K_{2}$ indicates that the higher energy sites had a much higher affinity for fluoride. ${ }^{48}$ This model showed higher predicted maximum adsorption capacity of fluoride to $8.96 \mathrm{mg} \mathrm{g}^{-1}$ at the $\mathrm{pH}$ of 7.0 and the temperature of $45^{\circ} \mathrm{C}$. The fluoride adsorption capacities of other natural adsorbents were previously reported. For example, the fluoride adsorption capacity was $0.122 \mathrm{mg} \mathrm{g}^{-1}$ and $0.226 \mathrm{mg} \mathrm{g}^{-1}$ for raw lamb bones and chicken bones, ${ }^{10} 2.71 \mathrm{mg} \mathrm{g}^{-1}$ for bone char, ${ }^{25} 7.32 \mathrm{mg} \mathrm{g}^{-1}$ for pyrolytic bone char at $700{ }^{\circ} \mathrm{C}^{26} 0.96 \mathrm{mg} \mathrm{g}^{-1}$ for activated alumina, ${ }^{25} 2.30 \mathrm{mg} \mathrm{g}^{-1}$ for activated alumina doped cellulose acetate phthalate (CAP) mixed matrix membrane, ${ }^{56} 3.192 \mathrm{mg}$ $\mathrm{g}^{-1}$ for aluminum impregnated coconut fiber ash, ${ }^{32} 5.16 \mathrm{mg} \mathrm{g}^{-1}$ for bauxite, ${ }^{46} 0.075 \mathrm{mg} \mathrm{g}^{-1}$ for activated carbon, ${ }^{25}$ respectively. Compared with other reported materials, LBW showed better performance on fluoride removal.

\subsection{Field study}

In this study, the feasibility of the LBW complex for defluoridation and the change in the concentrations of common
Table 7 Percentage desorption of fluoride from LBW composite by different concentrations $\mathrm{Na}_{2} \mathrm{CO}_{3}$ solution

\begin{tabular}{|c|c|}
\hline $\begin{array}{l}\mathrm{Na}_{2} \mathrm{CO}_{3} \text { solution } \\
\text { concentration }\left(\mathrm{mol} \mathrm{L}^{-1}\right)\end{array}$ & $\begin{array}{l}\text { Fluoride desorption } \\
\text { rate }(\%)\end{array}$ \\
\hline 1 & 92.96 \\
\hline $10^{-1}$ & 30.10 \\
\hline $10^{-2}$ & 8.19 \\
\hline $10^{-3}$ & 5.31 \\
\hline $10^{-4}$ & 4.87 \\
\hline
\end{tabular}

anions were also tested in actual groundwater. The fluoridecontaminated groundwater was collected from different locations (villages) near a mine area of Deyang City, Sichuan Province, China. The detailed results of these samples before and after addition of the LBW complex are presented in Table 6 . The high $\mathrm{F}^{-}$concentrations in groundwater were obtained in a bore well $\left(8.43 \mathrm{mg} \mathrm{L}^{-1}\right)$, spring $\left(4.49 \mathrm{mg} \mathrm{L}^{-1}\right)$ and dug well (3.43 $\mathrm{mg} \mathrm{L}^{-1}$ ) from a peasant household. It is not difficult to find that fluoride concentrations from sampling points were above drinking water standard (1.5 $\mathrm{mg} \mathrm{L}^{-1}$, WHO 2011). ${ }^{7}$ Longterm fluoride exposure in drinking water might cause adverse impacts on human health in this area.

Batch adsorption studies were also carried out under identical experimental conditions using $1.0 \mathrm{~g}$ of LBW for a $100 \mathrm{~mL}$ of sample, and the time of constant agitation was at $20 \mathrm{~min}$ at normal groundwater temperature $\left(15-18^{\circ} \mathrm{C}\right)$. It was found that the $\mathrm{F}^{-}$levels in three groundwater samples were less than drinking water standard $\left(1.5 \mathrm{mg} \mathrm{L}^{-1}\right.$, WHO 2011) after addition of the LBW complex. These results indicated that the LBW composite had little interference from other co-existing ions and showed better removal performance for fluoride especially at low concentrations. ${ }^{34}$ Furthermore, it is evident from Table 6 that the LBW composite could effectively remove bicarbonate $\left(\mathrm{HCO}_{3}{ }^{-}\right)$and phosphate $\left(\mathrm{PO}_{4}{ }^{3-}\right)$ from field groundwater simultaneously. The removal efficiency of sulfate $\left(\mathrm{SO}_{4}{ }^{2-}\right)$ by the LBW composite was higher than that of $\mathrm{NO}_{3}{ }^{-}$. These results were in conformity with the effect of co-existing oxygen anions

Table 6 The detailed results of actual groundwater samples before and after addition of the LBW ${ }^{a}$

\begin{tabular}{|c|c|c|c|c|c|c|}
\hline Parameters & Before adsorption & After adsorption & Before adsorption & After adsorption & Before adsorption & After adsorption \\
\hline Conductivity $\left(\mu \mathrm{cm}^{-1}\right)$ & 583 & 1063 & 579 & 1069 & 431 & 1004 \\
\hline Total hardness $\left(\mathrm{mg} \mathrm{L}^{-1}\right)$ & 359.36 & 490.49 & 328.33 & 460.46 & 222.22 & 429.43 \\
\hline $\mathrm{Cl}^{-}\left(\mathrm{mg} \mathrm{L}^{-1}\right)$ & 28.74 & ND & 28.39 & ND & 52.52 & ND \\
\hline $\mathrm{NO}_{3}^{-}\left(\mathrm{mg} \mathrm{L}^{-1}\right)$ & 19.96 & 18.30 & 22.39 & 21.22 & 0.35 & Nil \\
\hline $\mathrm{PO}_{4}{ }^{3-}\left(\mathrm{mg} \mathrm{L}^{-1}\right)$ & 6.35 & Nil & 0.28 & Nil & 0.28 & Nil \\
\hline $\mathrm{CO}_{3}^{2-}\left(\mathrm{mg} \mathrm{L}^{-1}\right)$ & Nil & Nil & Nil & Nil & Nil & Nil \\
\hline $\mathrm{HCO}_{3}{ }^{-}\left(\mathrm{mg} \mathrm{L}^{-1}\right)$ & 179.54 & 44.20 & 207.17 & 55.24 & 110.49 & 33.15 \\
\hline $\mathrm{F}^{-}\left(\mathrm{mg} \mathrm{L}^{-1}\right)$ & 8.43 & 0.33 & 4.49 & 0.28 & 3.43 & Nil \\
\hline
\end{tabular}

${ }^{a}$ ND: not detected above detection limit. Nil: not detected below detection limit. 


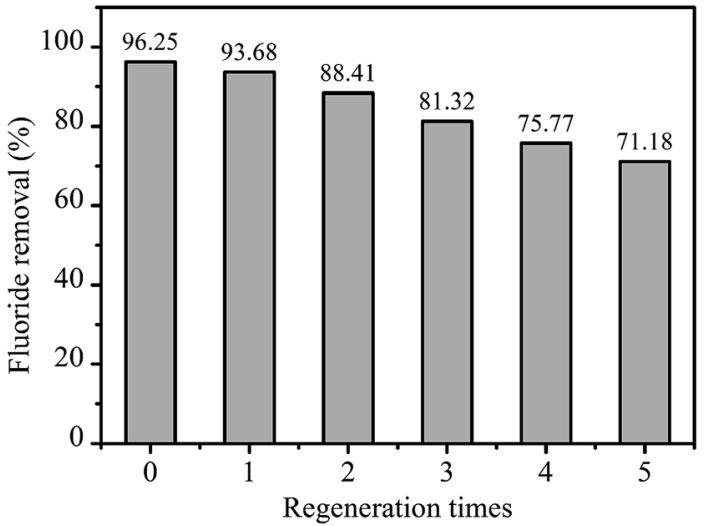

Fig. 9 Regeneration test of the adsorbent.

in Fig. 6 and Table 1. Thus, the LBW composite has the potential for practical application in fluoride-contaminated groundwater.

\subsection{Desorption and regeneration}

The above study suggested that fluoride was poorly adsorbed by LBW adsorbent in basic solution. Therefore, desorption of fluoride from the exhausted adsorbents can be easily obtained using slightly alkaline solution. ${ }^{39}$ In this research, desorption of fluoride from LBW composite was carried out with different concentrations of $\mathrm{Na}_{2} \mathrm{CO}_{3}$ solution. The fluoride desorption rates were listed in Table 7 , which showed that the released fluoride increased with the increase of $\mathrm{Na}_{2} \mathrm{CO}_{3}$ concentration. With the $\mathrm{Na}_{2} \mathrm{CO}_{3}$ concentration of $1 \mathrm{~mol} \mathrm{~L}^{-1}, 92.96 \%$ of fluoride was desorbed. Five consecutive adsorption-desorption cycles were performed to investigate the regeneration and recyclability of the LBW composite. The results were depicted in Fig. 9. When the initial fluoride concentration was $10 \mathrm{mg} \mathrm{L}^{-1}$, after five cycles, the fluoride removal were $93.68 \%, 88.41 \%, 81.32 \%$,
$75.77 \%$, and $71.18 \%$, respectively, which can be found that the value of fluoride removal changed small. Therefore, the adsorbent was suitable for regeneration and reusing.

\subsection{Mechanism of fluoride adsorption}

It was seen from kinetic studies that the fast adsorption rate and the short adsorption equilibrium time indicated that the density of active sites on the LBW composite was relatively high. ${ }^{39}$ SEM images showed an irregular surface and porous structure on LBW, and BET analysis revealed that the LBW composite had a large specific surface area $\left(85.4 \mathrm{~m}^{2} \mathrm{~g}^{-1}\right)$. These surface mesoporous and micropores aid fluoride adsorption. The XRD patterns confirmed the presence of lanthanum oxide or hydroxide in LBW composite, and the micro amount of La doped contributed to significant defluorination. The FTIR spectra confirmed the presence of abundant-OH groups on the LBW composite and the zeta potential showed a positively charged surface over a wide $\mathrm{pH}$ range $(\mathrm{pH}<11.4)$. Consequently, the protonation of these $-\mathrm{OH}$ groups and positively charged surface facilitated fluoride removal due to electrostatic attraction and ion exchange. The high resolution XPS spectra of $\mathrm{O}$ 1s and La $3 \mathrm{~d}$ showed that the content of hydroxyl groups $(-\mathrm{OH})$ reduced and the peaks of $\mathrm{La} 3 \mathrm{~d}$ shifted to the higher binding energy side after fluoride adsorption. These results indicated that fluoride ions might be removed by ion exchange between $\mathrm{F}^{-}$and $-\mathrm{OH}$ or $\mathrm{Cl}^{-}$on the LBW composite.

The possible mechanisms of fluoride adsorption on LBW composite are depicted in Fig. 10. Sodium ions in Na-BW promoted the composition between lanthanum ions and bone waste particles when $\mathrm{LaCl}_{3} \cdot n \mathrm{H}_{2} \mathrm{O}$ was added. This might form various forms of lanthanum, including $\mathrm{R}-\mathrm{La}-\mathrm{OH}, \mathrm{La}_{2} \mathrm{O}_{3}$ or $\mathrm{La}(\mathrm{OH})_{3}$, on the surface or in the mesoporous of the LBW composite through ion-exchange between $\mathrm{Na}^{+}$and $\mathrm{La}^{3+}$ ions. Multivalent metal ions, especially lanthanum, show a strong affinity towards fluoride ion, meaning the fluoride ions in the solution might get exchanged for the $\mathrm{OH}^{-}$or $\mathrm{Cl}^{-}$ions present in

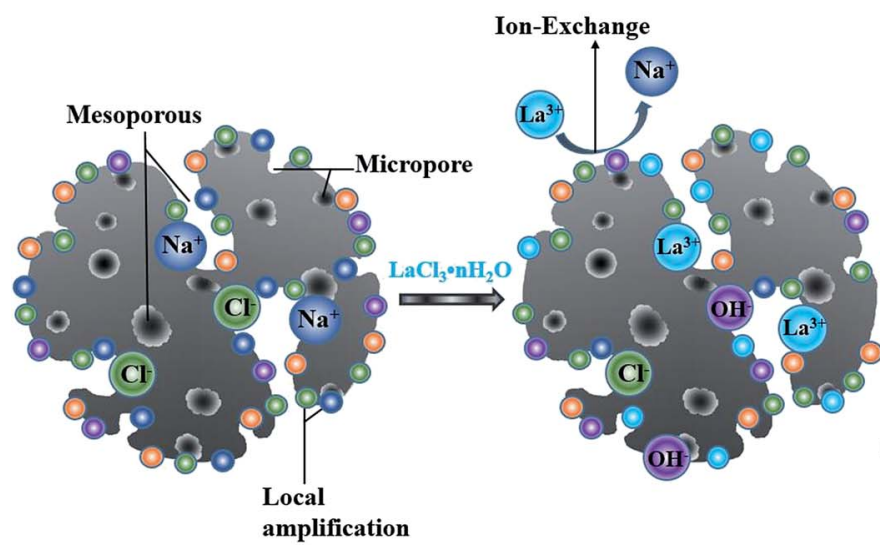

Na-BW

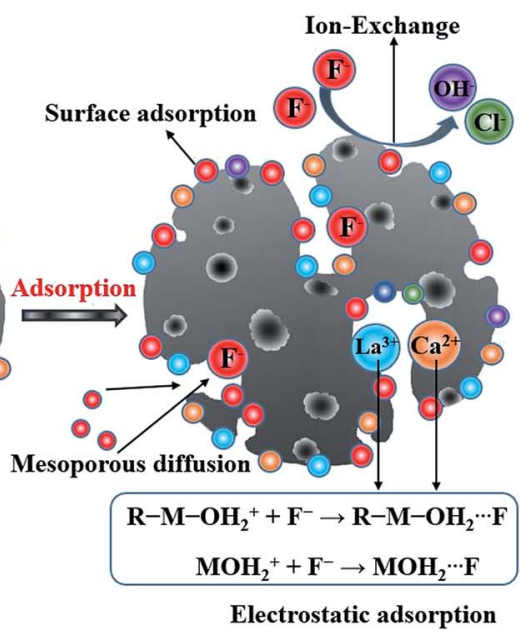

Fluoride Adsorption

Fig. 10 Schematic diagram of feasible defluoridation mechanism by LBW composite. 
the LBW composite. $\mathrm{F}^{-}$and $\mathrm{OH}^{-}$are isoelectronic with comparable ionic radii, thus the ion exchange between $\mathrm{F}^{-}$and $\mathrm{OH}^{-}$tended to happen and formed strong chemical bonds with $\mathrm{La}^{3+}$ or $\mathrm{Ca}^{2+}$ ions. ${ }^{57}$

$$
\begin{aligned}
\mathrm{R}-\mathrm{M}-\mathrm{OH}+\mathrm{F}^{-} & \rightarrow \mathrm{R}-\mathrm{M}-\mathrm{F}+\mathrm{OH}^{-} \\
\mathrm{M}-\mathrm{OH}+\mathrm{F}^{-} & \rightarrow \mathrm{M}-\mathrm{F}+\mathrm{OH}^{-} \\
\mathrm{M}-\mathrm{Cl}+\mathrm{F}^{-} & \rightarrow \mathrm{M}-\mathrm{F}+\mathrm{Cl}^{-}
\end{aligned}
$$

In addition, the metal ions were loaded on the adsorbent lattice and then a developed charged surface through amphoteric dissociation. ${ }^{58}$ Positively charged surface sites were maintained when the solution $\mathrm{pH}$ was less than the $\mathrm{pH}_{\mathrm{zpc}}$ of the adsorbent, which could attract the negatively charged fluoride ions by electrostatic attraction, resulting in enhanced fluoride removal. ${ }^{59}$ In this study, the presence of positively charged $\mathrm{Ca}^{2+}$ or $\mathrm{La}^{3+}$ ions in the LBW composite exhibited an attractive tendency towards the negatively charged fluoride ions by means of electrostatic adsorption forming organic fluoride bonded to metal (R-M-F) as follows:

$$
\begin{gathered}
\mathrm{R}-\mathrm{M}-\mathrm{OH}_{2}^{+}+\mathrm{F}^{-} \rightarrow \mathrm{R}-\mathrm{M}-\mathrm{OH}_{2} \cdots \mathrm{F} \\
\mathrm{MOH}_{2}^{+}+\mathrm{F}^{-} \rightarrow \mathrm{MOH}_{2} \cdots \mathrm{F}
\end{gathered}
$$

However, with the increase of solution $\mathrm{pH}$, the positively charged sites on the LBW surface reduced or even became negatively charged $\left(\mathrm{pH}>\mathrm{pH}_{\mathrm{zpc}}\right.$ ), leading to the weakening of protonated hydroxyl, and thus ion exchange between $\mathrm{F}^{-}$and $\mathrm{OH}^{-}$or $\mathrm{Cl}^{-}$might become the predominant defluorination mechanism.

\section{Conclusions}

In this study, a LBW composite was synthesized and tested to remove fluoride in aqueous solution. The introduction of lanthanum could improve the porous structure of the adsorbent and enhance the defluorination capacity of bone waste. The LBW composite had good temperature resistance and a buffer capacity for polluted water in an initial $\mathrm{pH}$ range of 2.5-10. Meanwhile, the LBW composite exhibited a good affinity for fluoride and the co-existing oxygen anions had hardly any adverse effects on fluoride removal in the range of 0 $100 \mathrm{mg} \mathrm{L}^{-1}$. The fluoride adsorption on the LBW composite was fast and the reaction could reach equilibrium within $20 \mathrm{~min}$. Kinetic studies revealed that the adsorption followed PSO and FL PSO equations well, indicating that it was a typical chemisorption process. The FVER model provided a more accurate prediction of the kinetic adsorption data in the whole time range to comparing with the VER model. Isotherm studies showed that the fluoride adsorption was monolayer adsorption occurred on homogeneous LBW surface and the maximum adsorption capacity was about $8.96 \mathrm{mg} \mathrm{g}^{-1}$. The results of desorption and reuse research indicated that the LBW adsorbent could be employed as a promising adsorbent for fluoride removal from groundwater. The possible mechanism might be the combination of electrostatic attraction and ion exchange. In summary, the LBW composite provides the potential of practical application for fluoride removal from contaminated groundwater.

\section{Conflicts of interest}

There are no conflicts to declare.

\section{Acknowledgements}

This work was supported by grants from the Chinese National Natural Science Foundations (No. 51109019).

\section{References}

1 S. Dong and Y. Wang, Characterization and adsorption properties of a lanthanum-loaded magnetic cationic hydrogel composite for fluoride removal, Water Res., 2016, 88, 852-860.

2 S. Kanrar, S. Debnath, P. De, K. Parashar, K. Pillay, P. Sasikumar and U. C. Ghosh, Preparation, characterization and evaluation of fluoride adsorption efficiency from water of iron-aluminium oxide-graphene oxide composite material, Chem. Eng. J., 2016, 306, 269-279.

3 M. Koteswara Rao and M. Mallikarjun, Effective low cost adsorbents for removal of fluoride from water: A review, Int. J. Sci. Res., 2014, 3, 1-5.

4 A. Bhatnagar, E. Kumar and M. Sillanpää, Fluoride removal from water by adsorption - A review, Chem. Eng. J., 2011, 171, 811-840.

5 K. Babaeivelni and A. P. Khodadoust, Adsorption of fluoride onto crystalline titanium dioxide: Effect of $\mathrm{pH}$, ionic strength, and co-existing ions, J. Colloid Interface Sci., 2013, 394, 419-427.

$6 \mathrm{~J}$. He and J. P. Chen, A zirconium-based nanoparticle: Essential factors for sustainable application in treatment of fluoride containing water, J. Colloid Interface Sci., 2014, 416, 227-234.

7 World Health Organization, Guidelines for drinking water quality, 4th edn, 2011.

8 J. He, T. S. Siah and J. P. Chen, Performance of a n optimized Zr-based nanoparticle-embedded PSF blend hollow fiber membrane in treatment of fluoride contaminated water, Water Res., 2014, 56, 88-97.

9 H. Huang, J. Liu, P. Zhang, D. Zhang and F. Gao, Investigation on the simultaneous removal of fluoride, ammonia nitrogen and phosphate from semiconductor wastewater using chemical precipitation, Chem. Eng. J., 2017, 307, 696-706.

10 Z. Z. Ismail and H. N. AbdelKareem, Sustainable approach for recycling waste lamb and chicken bones for fluoride removal from water followed by reusing fluoride-bearing waste in concrete, Waste Manag., 2015, 45, 66-75.

11 L. S. Thakur and P. Mondal, Simultaneous arsenic and fluoride removal from synthetic and real groundwater by 
electrocoagulation process: Parametric and cost evaluation, J. Environ. Manage., 2017, 190, 102-112.

$12 \mathrm{~N}$. Viswanathan and S. Meenakshi, Role of metal ion incorporation in ion exchange resin on the selectivity of fluoride, J. Hazard. Mater., 2009, 162, 920-930.

$13 \mathrm{~J}$. Shen and A. Schäfer, Removal of fluoride and uranium by nanofiltration and reverse osmosis: A review, Chemosphere, 2014, 117, 679-691.

14 L. J. Banasiak and A. I. Schäfer, Removal of boron, fluoride and nitrate by electrodialysis in the presence of organic matter, J. Membr. Sci., 2009, 334, 101-109.

15 M. Zendehdel, B. Shoshtari-Yeganeh, H. Khanmohamadi and G. Cruciani, Removal of fluoride from aqueous solution by adsorption on NaP: HAp nanocomposite using response surface methodology, Process Saf. Environ. Prot., 2017, 109, 172-191.

$16 \mathrm{~J}$. Cheng, X. Meng, C. Jing and J. Hao, $\mathrm{La}^{3+}$-modified activated alumina for fluoride removal from water, $J$. Hazard. Mater., 2014, 278, 343-349.

17 R. Leyva-Ramos, J. Rivera-Utrilla, N. A. Medellin-Castillo and M. Sanchez-Polo, Kinetic modeling of fluoride adsorption from aqueous solution onto bone char, Chem. Eng. J., 2010, 158, 458-467.

18 M. Mourabet, A. El Rhilassi, H. El Boujaady, M. BennaniZiatni, R. El Hamri and A. Taitai, Removal of fluoride from aqueous solution by adsorption on hydroxyapatite (HAp) using response surface methodology, J. Saudi Chem. Soc., 2015, 19, 603-615.

19 Q. Liu, L. Zhang, B. Yang and R. Huang, Removal of fluoride from aqueous solution using $\mathrm{Zr}$ (IV) immobilized cross-linked chitosan, Int. J. Biol. Macromol., 2015, 77, 15-23.

20 P. Wu, L. Xia, M. Dai, L. Lin and S. Song, Electrosorption of fluoride on $\mathrm{TiO}_{2}$-loaded activated carbon in water, Colloids Surf., A, 2016, 502, 66-73.

21 S. I. Zones and S. J. Hwang, A novel approach to borosilicate zeolite synthesis in the presence of fluoride, Microporous Mesoporous Mater., 2011, 146, 48-56.

22 N. M. Zúñiga-Muro, A. Bonilla-Petriciolet, D. I. MendozaCastillo, H. E. Reynel-Ávila and J. C. Tapia-Picazo, Fluoride adsorption properties of cerium-containing bone char, $J$. Fluorine Chem., 2017, 197, 63-73.

23 N. A. Medellin-Castillo, R. Leyva-Ramos, E. Padilla-Ortega, R. O. Perez, J. V. Flores-Cano and M. S. Berber-Mendoza, Adsorption capacity of bone char for removing fluoride from water solution. Role of hydroxyapatite content, adsorption mechanism and competing anions, J. Ind. Eng. Chem., 2014, 20, 4014-4021.

24 J. He, K. Zhang, S. Wu, X. Cai, K. Chen, Y. Li, B. Sun, Y. Jia, F. Meng, Z. Jin, L. Kong and J. Liu, Performance of novel hydroxyapatite nanowires in treatment of fluoride contaminated water, J. Hazard. Mater., 2016, 303, 119-130.

25 N. A. Medellin-Castillo, R. Leyva-Ramos, R. Ocampo-Perez, R. F. Garcia de la Cruz, A. Aragon-Pina, J. M. MartinezRosales, R. M. Guerrero Coronado and L. Fuentes-Rubio, Adsorption of fluoride from water solution on bone char, Ind. Eng. Chem. Res., 2007, 46, 9205-9212.
26 C. K. Rojas-Mayorga, A. Bonilla-Petriciolet, I. A. AguayoVillarreal, V. Hernández-Montoya, M. R. Moreno-Virgen, R. Tovar-Gómez and M. A. Montes-Morán, Optimization of pyrolysis conditions and adsorption properties of bone char for fluoride removal from water, J. Anal. Appl. Pyrolysis, 2013, 104, 10-18.

$27 \mathrm{~T}$. Wu, L. Mao and H. Wang, Adsorption of fluoride from aqueous solution by using hybrid adsorbent fabricated with $\mathrm{Mg} / \mathrm{Fe}$ composite oxide and alginate via a facile method, J. Fluorine Chem., 2017, 200, 8-17.

28 Y. Zhang, X. Lin, Q. Zhou and X. Luo, Fluoride adsorption from aqueous solution by magnetic core-shell $\mathrm{Fe}_{3} \mathrm{O}_{4} @$ alginate-La particles fabricated via electrocoextrusion, Appl. Surf. Sci., 2016, 389, 34-45.

29 G. Zhang, X. Ding, F. He, X. Yu, J. Zhou, Y. Hu and J. Xie, Low-temperature synthesis and photocatalytic activity of $\mathrm{TiO}_{2}$ pillared montmorillonite, Langmuir, 2008, 24, 10261030.

30 G. Zhang, Y. Gao, Y. Zhang and Y. Guo, $\mathrm{Fe}_{2} \mathrm{O}_{3}$-pillared rectorite as an efficient and stable Fenton-like heterogeneous catalyst for photodegradation of organic contaminants, Environ. Sci. Technol., 2010, 44, 6384-6389.

31 G. Zhang, Z. He and W. Xu, A low-cost and high efficient zirconium-modified-Na-attapulgite adsorbent for fluoride removal from aqueous solutions, Chem. Eng. J., 2012, 183, 315-324.

32 N. K. Mondal, R. Bhaumik and J. K. Datta, Removal of fluoride by aluminum impregnated coconut fiber from synthetic fluoride solution and natural water, Alexandria Eng. J., 2015, 54, 1273-1284.

33 M. M. Labani, R. Rezaee, A. Saeedi and A. A. Hinai, Evaluation of pore size spectrum of gas shale reservoirs using low pressure nitrogen adsorption, gas expansion and mercury porosimetry: A case study from the Perth and Canning Basins, Western Australia, J. Pet. Sci. Eng., 2013, 112, 7-16.

34 A. Bansiwal, D. Thakre, N. Labhshetwar, S. Meshram and S. Rayalu, Fluoride removal using lanthanum incorporated chitosan beads, Colloids Surf., B, 2009, 74, 216-224.

35 E. V. Alvares, L. H. V. Jimenez, L. F. C. Ruiz, P. E. D. Flores and J. R. R. Mendez, Fluoride removal in water by a hybrid adsorbent lanthanum-carbon, J. Colloid Interface Sci., 2015, 455, 194-202.

36 E. Christina and P. Viswanathan, Development of a novel nano-biosorbent for the removal of fluoride from water, Chin. J. Chem. Eng., 2015, 23, 924-933.

37 L. Chen, K. S. Zhang, J. Y. He, W. H. Xu, X. J. Huang and J. H. Liu, Enhanced fluoride removal from water by sulfatedoped hydroxyapatite hierarchical hollow microspheres, Chem. Eng. J., 2016, 285, 616-624.

38 W. Liang, L. Zhan, L. H. Piao and C. Rüssel, Fluoride removal performance of glass derived hydroxyapatite, Mater. Res. Bull., 2011, 46, 205-209.

39 Y. Liu, Q. Fan, S. X. Wang, Y. L. Liu, A. L. Zhou and L. Fan, Adsorptive removal of fluoride from aqueous solutions using Al-humic acid-La aerogel composites, Chem. Eng. J., 2016, 306, 174-185. 
40 Y. Jia, B. Zhu, K. Zhang, Z. Jin, B. Sun, T. Luo, X. Yu, L. Kong and J. Liu, Porous 2-line ferrihydrite/bayerite composites (LFBC): Fluoride removal performance and mechanism, Chem. Eng. J., 2015, 268, 325-336.

$41 \mathrm{X}$. Wu, Y. Zhang, X. Dou, B. Zhao and M. Yang, Fluoride adsorption on an Fe-Al-Ce trimetal hydrous oxide: Characterization of adsorption sites and adsorbed fluorine complex species, Chem. Eng. J., 2013, 223, 364-370.

42 P. Koilraj and K. Sasaki, Selective removal of phosphate using La-porous carbon composites from aqueous solutions: Batch and column studies, Chem. Eng. J., 2017, 317, 1059-1068.

43 A. K. Samal and T. Pradeep, Lanthanum telluride nanowires: Formation, doping, and Raman studies, J. Phys. Chem. C, 2010, 114, 5871-5878.

44 Z. Hu, X. Hu, Q. Liang, Z. Tong, F. Han and X. Yang, Modern Chemistry Foundation, Higher Education Press, Beijing, 4th edn, 2014.

$45 \mathrm{Q} . \mathrm{Hu}, \mathrm{N}$. Chen, C. Feng and W. Hu, Kinetic studies for nitrate adsorption on granular chitosan-Fe(III) complex, Desalin. Water Treat., 2016, 57, 27783-27793.

46 M. G. Sujana and S. Anand, Fluoride removal studies from contaminated ground water by using bauxite, Desalination, 2011, 267, 222-227.

47 D. Tang and G. Zhang, Efficient removal of fluoride by hierarchical Ce-Fe bimetal oxides adsorbent: Thermodynamics, kinetics and mechanism, Chem. Eng. J., 2016, 283, 721-729.

48 L. Chai, Y. Wang, N. Zhao, W. Yang and X. You, Sulfatedoped $\mathrm{Fe}_{3} \mathrm{O}_{4} / \mathrm{Al}_{2} \mathrm{O}_{3}$ nanoparticles as a novel adsorbent for fluoride removal from drinking water, Water Res., 2013, 47, 4040-4049.

49 J. Zhang, N. Chen, Z. Tang, Y. Yu, Q. Hu and C. Feng, A study of the mechanism of fluoride adsorption from aqueous solutions onto Fe-impregnated chitosan, Phys. Chem. Chem. Phys., 2015, 17, 12041-12050.
50 E. Kumar, A. Bhatnagar, M. Ji, W. Jung, S. H. Lee, S. J. Kim, G. Lee, H. Song, J. Y. Choi, J. S. Yang and B. H. Jeon, Defluoridation from aqueous solutions by granular ferric hydroxide (GFH), Water Res., 2009, 43, 490-498.

51 J. Ma, Y. Shen, C. Shen, Y. Wen and W. Liu, Al-doping chitosan-Fe(III) hydrogel for the removal of fluoride from aqueous solutions, Chem. Eng. J., 2014, 248, 98-106.

52 M. Haerifar and S. Azizian, Fractal-Like kinetics for adsorption on heterogeneous solid surfaces, J. Phys. Chem. C, 2014, 118, 1129-1134.

53 M. Balsamo and F. Montagnaro, Fractal-like Vermeulen kinetic equation for the description of diffusion-controlled adsorption dynamics, J. Phys. Chem. C, 2015, 119, 8781-8785.

54 A. K. Bhattacharya, S. N. Mandal and S. K. Das, Adsorption of $\mathrm{Zn}$ (II) from aqueous solution by using different adsorbents, Chem. Eng. J., 2006, 123, 43-51.

55 S. F. Montanher, E. A. Oliveira and M. C. Rollemberg, Removal of metal ions from aqueous solutions by sorption onto rice bran, J. Hazard. Mater., 2005, 117, 207-211.

56 S. Chatterjee and S. De, Adsorptive removal of fluoride by activated alumina doped cellulose acetate phthalate (CAP) mixed matrix membrane, Sep. Purif. Technol., 2014, 125, 223-238.

57 S. K. Swain, T. Patnaik, P. C. Patnaik, U. Jha and R. K. Dey, Development of new alginate entrapped Fe(III)-Zr(Iv) binary mixed oxide for removal of fluoride from water bodies, Chem. Eng. J., 2013, 215-216, 763-771.

58 P. Loganathan, S. Vigneswaran, J. Kandasamy and R. Naidu, Defluoridation of drinking water using adsorption processes, J. Hazard. Mater., 2013, 248-249, 1-19.

$59 \mathrm{~K}$. Pandi and N. Viswanathan, In situ fabrication of magnetic iron oxide over nano-hydroxyapatite gelatin eco-polymeric composite for defluoridation studies, J. Chem. Eng. Data, 2016, 61, 571-578. 